\title{
WestVirginiaUniversity
}

THE RESEARCH REPOSITORY @ WVU

Graduate Theses, Dissertations, and Problem Reports

2002

\section{Thermodynamic effects of phospholamban on Ca-ATPase kinetics}

Patrick L. Apopa

West Virginia University

Follow this and additional works at: https://researchrepository.wvu.edu/etd

\section{Recommended Citation}

Apopa, Patrick L., "Thermodynamic effects of phospholamban on Ca-ATPase kinetics" (2002). Graduate Theses, Dissertations, and Problem Reports. 1570.

https://researchrepository.wvu.edu/etd/1570

This Thesis is protected by copyright and/or related rights. It has been brought to you by the The Research Repository @ WVU with permission from the rights-holder(s). You are free to use this Thesis in any way that is permitted by the copyright and related rights legislation that applies to your use. For other uses you must obtain permission from the rights-holder(s) directly, unless additional rights are indicated by a Creative Commons license in the record and/ or on the work itself. This Thesis has been accepted for inclusion in WVU Graduate Theses, Dissertations, and Problem Reports collection by an authorized administrator of The Research Repository @ WVU. For more information, please contact researchrepository@mail.wvu.edu. 


\title{
Thermodynamic Effects of Phospholamban on Ca-ATPase Kinetics
}

\author{
Patrick L. Apopa
}

Thesis Submitted to the School of Medicine at West Virginia University in partial fulfillment of the requirements for the degree of

\author{
Master of Science \\ In \\ Biochemistry
}

\author{
James Mahaney, Ph.D., Chair \\ Lisa Salati, Ph.D. \\ Grazyna Szklarz, Ph.D \\ William Wonderlin, Ph.D. \\ Department of Biochemistry and Molecular Pharmacology \\ Morgantown, WV \\ 2002
}

Keywords: Ca-ATPase, phospholamban, activation energy, phosphoenzyme, baculovirusinsect cell expression system

Copyright 2002 Patrick L. Apopa 


\section{ABSTRACT \\ Thermodynamic Effects of Phospholamban on Ca-ATPase Kinetics}

\section{Patrick L. Apopa}

The Ca-ATPase of sarcoplasmic reticulum removes cytosolic calcium to promote muscle relaxation. In the heart, the Ca-ATPase is regulated by phospholamban, which inhibits the Ca-ATPase by decreasing Ca-ATPase calcium sensitivity. However, the kinetic and thermodynamic mechanisms of inhibition are not understood. The purpose of this research was to test the hypothesis that phospholamban regulates $\mathrm{Ca}$-ATPase kinetics by increasing Ca-ATPase activation energy. The baculovirus-insect cell expression system was used to produce samples containing Ca-ATPase alone or Ca-ATPase with phospholamban. The temperature-dependence of Ca-ATPase activity and catalytic site density was measured in the absence and presence of phospholamban at sub-saturating calcium and used to calculate the temperature-dependence of Ca-ATPase turnover. Arrhenius analyses showed that phospholamban increased Ca-ATPase activation energy from $31 \pm 3 \mathrm{~J} / \mathrm{mol}$ (Ca-ATPase only) to $52 \pm 5 \mathrm{~J} / \mathrm{mol}$ (Ca-ATPase + phospholamban). The results supported the hypothesis and provided new insight into the mechanism of phospholamban inhibition of Ca-ATPase. 


\section{Dedication}

To my wife Jackie and Daughter Joy 


\section{Acknowledgements}

I wish to express my appreciation and sincere thanks to Dr. Jim Mahaney, whom I have had as my advisor since I joined this program. I have benefited tremendously from his advice, discussions and encouragement during the entire course of this study. He made learning such a wonderful experience for me. I was most spirited by his patience and encouragement during difficult times.

I want to thank Drs. Wonderlin, Szklarz and Salati for agreeing to serve on my committee at a very short notice.

My sincere appreciation and thanks also go to my Lab colleagues for their time, support and friendship that made working with them just fun. I particularly want to thank Jammie Huffman for tirelessly doing the cell work and making sure I had enough good samples to do my experiments. The assistance given to me by Jason Waggoner and Jason Southall is greatly acknowledged; I owe them many thanks. A lot of thanks also goes to Konni Turner for all the help she gave to me during my entire stay in the Lab and for everything she did ranging from $\mathrm{pCa}$ assays to washing dishes to organizing Lab events like picnics, lunches and candy. Your contribution added to my happy stay in the Lab.

I would like to thank all the graduate students (past and present) in the department of Biochemistry and Molecular pharmacology with whom I have had and continue to have helpful interactions, both intellectual and social through the course of this work.

Also, I would like to thank the entire faculty and staff of the Department of Biochemistry and Molecular Pharmacology for all their help during this work.

Finally, special thanks are due to my family, my wife Jackie and daughter Joy for their patience and Love all the time. 


\section{Table of Contents}

$\begin{array}{lll}\text { Abstract } & \text { ii }\end{array}$

Dedication

Acknowledgements vii

List of Figures vii

List of Abbreviations viii

Chapter 1: Introduction 1

$\mathrm{Ca}^{2+}$-ATPase $\quad 8$

$\begin{array}{ll}\text { Mechanism of } \mathrm{Ca}^{2+} \text {-ATPase } & 10\end{array}$

$\begin{array}{ll}\text { Phosphorylation of the ATPase } & 14\end{array}$

$\begin{array}{ll}\text { Phospholamban (PLB) } & 15\end{array}$

$\begin{array}{ll}\text { Overview of the Thesis research } & 18\end{array}$

$\begin{array}{ll}\text { Aim } 1 & 19\end{array}$

$\begin{array}{ll}\text { Aim } 2 & 20\end{array}$

$\begin{array}{ll}\text { Aim } 3 & 20\end{array}$

$\begin{array}{ll}\text { Chapter 2: Methods } & 21\end{array}$

$\begin{array}{ll}\text { Reagents and solutions } & 21\end{array}$

$\begin{array}{ll}\text { Protein expression and isolation } & 21\end{array}$

Electrophoresis and immunoblotting $\quad 22$

$\begin{array}{ll}\text { Ca-ATPase activity assays } & 23\end{array}$

Ca-ATPase phosphoenzyme levels 25

$\begin{array}{ll}\text { Chapter 3: Results } & 27\end{array}$

$\begin{array}{ll}\text { Protein Expression, Characterization and Assay } & 27\end{array}$

Effect of Phospholamban on the Temperature-dependence of

Ca-ATPase Activity 31

Effect of Phospholamban on the Temperature-dependence of Ca-ATPase EP formation $\quad 34$

Effect of Phospholamban on Ca-ATPase Activation Energy 37 
Chapter 4: Discusion $\quad 41$

$\begin{array}{ll}\text { Overview } & 41\end{array}$

The baculovirus-insect cell Ca-ATPase / phospholamban

$\begin{array}{ll}\text { Expression system } & 41\end{array}$

Ca-ATPase turnover number $\quad 42$

Effect of phospholamban on Ca-ATPase Activation Energy 43

Anti-phospholamban Antibody had no effect on $\mathrm{Ca}^{2+}$-ATPase activity 47

Chapter 5: References $\quad 51$

Appendix $\quad 56$

Permission to use copyright material from Nature $\quad 56$

Permission to us copyright material from authors $\quad 57$

$\begin{array}{lr}\text { Curriculum vitae } & 58\end{array}$ 


\section{List of Figures}

\section{Chapter 1}

Figure 1: A schematic of myocyte action potential 3

Figure 2: $\quad$ Secondary structure of the $\mathrm{Ca}^{2+}$-ATPase 9

Figure 3: $\quad 2.6$ Angstrom Structure of the Ca-ATPase 11

Scheme1: $\quad$ E1/E2 Scheme for the $\mathrm{Ca}^{2+}$-ATPase 13

\section{Chapter 3}

Figure 4: $\quad$ SDS-PAGE and immunoblot of SERCA2a and

phospholamban in cardiac SR vesicles and High Five insect cell microsomes $\quad 29$

Figure 5: $\quad$ Effect of Phospholamban on $\mathrm{Ca}^{2+}$-ATPase activity at $37^{0} \mathrm{C} 32$

Figure 6: $\quad$ Effect of phospholamban on temperature dependence of $\mathrm{Ca}^{2+}$ ATPase activity 35

Figure 7: $\quad$ Effect of phospholamban on temperature dependence of $\mathrm{Ca}^{2+}$ ATPase turnover number $\left(\mathrm{K}_{\mathrm{cat}}\right)$, Arrhenius Analysis 39

\section{Chapter 4}

Figure 8: $\quad$ Phospholamban as an allosteric modulator of Ca-ATPase 45 


\section{List of Abbreviations}

2A7-A1 monoclonal antibody against Ca-ATPase

2D12 monoclonal antibody against phospholamban

CSR cardiac sarcoplasmic reticulum

EGTA ethylene glycol bis((-aminoethyl ether)- $N, N, N^{\prime}, N^{\prime}$-tetraacetic acid

EP phosphoenzyme

$\mathrm{k}_{\mathrm{cat}} \quad$ turnover number, Ca-ATPase activity divided by steady-state EP level

$\mathrm{K}_{\mathrm{ca}}$ value ionized $\left[\mathrm{Ca}^{2+}\right]$ giving half-maximal activation of the Ca-ATPase

MOPS 3-(N-morpholino)propanesulfonic acid

PLB phospholamban

SDS-PAGE sodium dodecyl sulfate polyacrylamide gel electrophoresis

SERCA sarco(endo)plasmic reticulum Ca-ATPase

SR, CSR sarcoplasmic reticulum, cardiac sarcoplasmic reticulum 


\section{Chapter 1: Introduction}

There is a high prevalence of heart disease worldwide and mortality due to heart related ailments is on the rise. There is a need for increased understanding of the etiologic mechanisms associated with these varieties of cardiac dysfunction, and this should translate to a more targeted therapy.

The heart tissue is composed of different cell types, namely the smooth muscle cells, fibroblasts and cardiac myocytes. The cardiac myocytes are the contractile cells of the heart. It is prudent therefore to understand the structural component of the myocyte in relation to its function. The myocytes are surrounded by a basement membrane, which is composed primarily of type I collagen, the glycoproteins laminin and fibronectin and proteoglycans. The basement membrane provides a barrier that influences the exchange of macromolecules between the extracellular space and the cell. It also provides an interface for cell adhesion and continuity with intracellular matrix. There is also the sarcolemma, which consists of the plasma membrane and the basement membrane. The sarcolemma is composed of the lipid bilayer, which contains hydrophilic heads and hydrophobic tails. This composition allows it to interact with intracellular and extracellular environment. The hydrophobic tails however, make the sarcolemma impermeable to charged molecules. The sarcolemma forms two specialized regions of the myocyte, the intercalated disc and the transverse tubular system. The intercalated disc has a specialized cell-cell junction, which functions as a strong mechanical linkage between myocytes yet has low resistance to allow for rapid conduction of action potential between myocytes. 
The transverse tubules, (or T-tubules) are invaginations of the sarcolemma into the myocytes, which form a barrier between the intracellular and the extracellular spaces. These extensions bring in close apposition the L-type $\mathrm{Ca}^{2+}$ channels and the sarcoplasmic reticulum $\mathrm{Ca}$ discharge system and this makes the T-tubular system an important structural component in excitation-contraction coupling.

The major component of the sarcolemma is the lipid bilayer. Therefore, as with other lipid bilayers, it provides a barrier for diffusion. The sarcolemma contains various membrane proteins, which include receptors, pumps and channels. This specialized feature of the sarcolemma is essential to the contractile process of the myocyte (Walker and Spinale, 1999). The pumps and channels of the myocyte sarcolemma can be best reviewed when placed in the context of the phases of action potential represented in Figure 1.

The resting membrane potential or phase 4 of the action potential is maintained primarily by the inward $\mathrm{K}^{+}$rectifier and secondarily influenced by the $\mathrm{Na}^{+} / \mathrm{K}^{+}$adenosine triphosphatase (ATPase). During the resting membrane potential, the sarcolemma is only permeable to $\mathrm{K}^{+}$, thus it is the $\mathrm{K}^{+}$equilibrium potential that determines the resting membrane potential of the myocyte. The inward $\mathrm{K}^{+}$rectifier allows for the $\mathrm{K}^{+}$diffusion into the cardiac myocytes. The $\mathrm{Na}^{+} / \mathrm{K}^{+}$ATPase then generates an outward current through the extrusion of three $\mathrm{Na}^{+}$ions for two $\mathrm{K}^{+}$ions to maintain the resting potential. There is also the $\mathrm{Na}^{+} / \mathrm{Ca}^{2+}$ exchanger and the sarcolemmal $\mathrm{Ca}^{2+}$-ATPase, which provide the basis for $\mathrm{Ca}^{2+}$ extrusion from the myocyte. $\mathrm{The}^{+} / \mathrm{Ca}^{2+}$ exchange is a bidirectional channel; with the relative amounts of either ion carried across the membrane determined by the concentration o either side of the membrane (Philipson, 1990). 


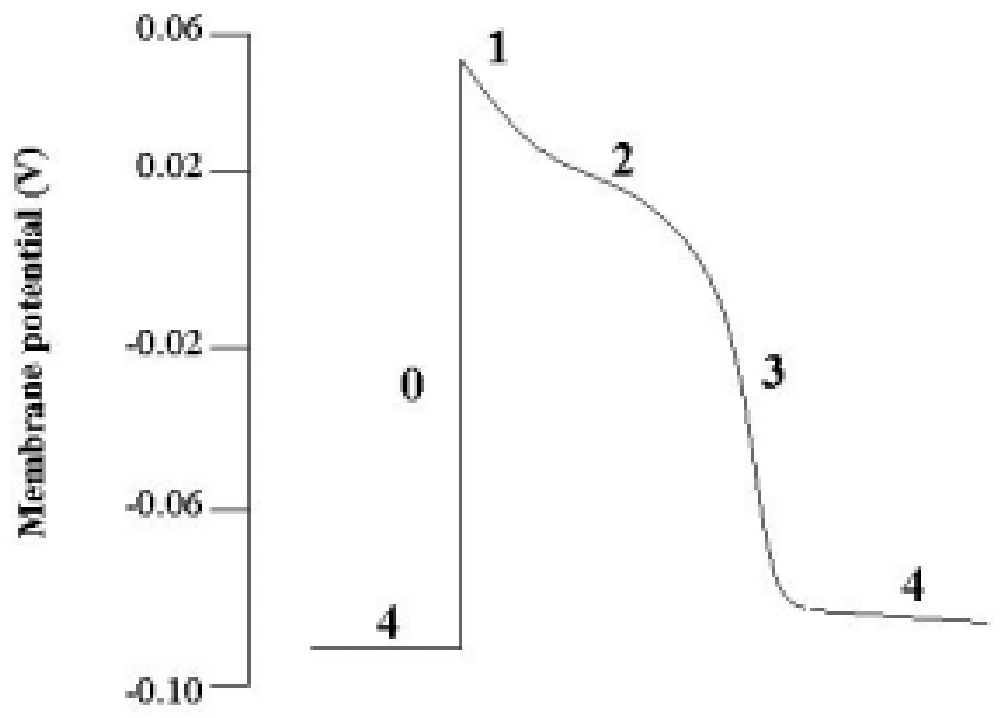

Figure 1: A schematic of myocyte action potential. The cardiac action potential consists of 5 phases. Phase 0 , the upstroke, correspond to rapid depolarization. The upstroke is followed by phase 1, a brief early repolarization, phase 2 or plateau, phase 3 or rapid repolarization and phase 4 , which correspond to the resting membrane potential. This action potential is the result of sarcolemmal protein interactions that have been summarized in the text. 
During the action potential, the upstroke of phase 0 (Figure 1) is created by the fast $\mathrm{Na}^{+}$channel. In an all or non-mechanism, this upstroke occurs when the membrane potential achieves a preset threshold voltage and the $\mathrm{Na}^{+}$channels rapidly activate $(<1 \mathrm{~ms})$. The channel remains activated for duration of only $2-10 \mathrm{~ms}$, thus the name 'fast' $\mathrm{Na}^{+}$channel. This activation allows $\mathrm{Na}^{+}$to flow into the cell along both electrical and chemical concentration gradients. This influx of $\mathrm{Na}^{+}$through the fast $\mathrm{Na}^{+}$channel triggers the ionic processes responsible for the other phases of the action potential (Walker and Spinale, 1999). Rapid inactivation of $\mathrm{Na}^{+}$channels and slower activation of two outward currents are the basis for early repolariztion (phase 1). The positive membrane potential, the $\mathrm{Cl}^{-}$concentration gradient, and increased membrane permeability to $\mathrm{Cl}^{-}$allows for the entry of $\mathrm{Cl}^{-}$into the cell. A transient efflux of $\mathrm{K}^{+}$through specific channels occurs along the $\mathrm{K}^{+}$electrochemical gradient. All these three events are responsible for the brief and small repolarization of the membrane potential during phase 1 of action potential.

Phase 2 of the action potential is mainly determined by the influx of $\mathrm{Ca}^{2+}$ through the L-type $\mathrm{Ca}^{2+}$ channels (Balke and Shorofsky, 1997). Additionally, there is a counterbalancing outward $\mathrm{K}^{+}$current that flows through the 'anomalous' $\mathrm{K}^{+}$rectifier (Katz, 1992). These channels are both activated during the upstroke of the action potential and reach peak current concurrently during phase 2 of the action potential.

Phase 3 of the action potential, which is the repolarization phase, is the result of increased $\mathrm{K}^{+}$conductance through the delayed rectifier $\mathrm{K}^{+}$channel. These channels are activated towards the end of phase 2 and they allow $\mathrm{K}^{+}$ion to flow out of the cell along the concentration gradient. At this stage of the action potential, the other inward currents, 
$\mathrm{Na}^{+}$and $\mathrm{Ca}^{2+}$ are inactivated, making the delayed rectifying $\mathrm{K}^{+}$current responsible for the restoration of the membrane potential to the resting state.

The excitation-contraction coupling is the mechanism by which the action potential leads to contraction of the myocyte. It is basically achieved through an increase in cytosolic $\mathrm{Ca}^{2+}$ levels from nanomolar to micromolar concentrations (Berne and Levy, 1997).

Calcium is pivotal to regulation of the rhythmic contraction/relaxation cycle in the heart. Ultrastructural evidence indicates that the L-type calcium channels embedded in the transverse tubules are functionally and physically associated with the ryanodine receptors/ $\mathrm{Ca}^{2+}$ release channels on the sarcoplasmic reticulum (SR) in contractile muscle. In cardiac myocytes, communication between the L-type $\mathrm{Ca}^{2+}$ channel and ryanodine receptor stimulate release of $\mathrm{Ca}^{2+}$ from the SR. This is known as the $\mathrm{Ca}^{2+}-$ induced $\mathrm{Ca}^{2+}$ release (CICR) mechanism. This is where the action potential reaches the myocyte and a wave of depolarization at the T-tubular system result in the activation of the sarcolemmal voltage sensitive $\mathrm{Ca}^{2+}$ channel, also referred to as the dihydropyridine receptor (DHPR) and leads to Ca conductance (Mukherjee and Spinale, 1998). This rapid but small influx of $\mathrm{Ca}^{2+}$ through the L-type $\mathrm{Ca}^{2+}$ channels causes activation of $\mathrm{Ca}^{2+}$ release channels which then release large amounts of $\mathrm{Ca}^{2+}$ into the cytosol (Berrige, 1997; Bers, 1991).

For CICR to produce optimal response, it is postulated that either larger calcium releases must inactivate the $\mathrm{Ca}^{2+}$ release channels (Fabiato, 1985), or the released calcium must dissipate rapidly from the vicinity of the ryanodine receptor during random and calcium-independent close intervals of the release channels (Morad and Cleeman, 1987). 
The increase in the cytosolic $\mathrm{Ca}^{2+}$ level results in the $\mathrm{Ca}^{2+}$ binding to the Troponin complex and following the release of $\mathrm{Ca}^{2+}$ from the sarcoplasmic reticulum, a series of interactions occur within the contractile proteins of the sarcomere that serves as the fundamental basis of muscle contraction (Berne et al., 1997). The fundamental proteins of the contractile apparatus are myosin, actin, tropomyosin and the troponin complex. Myosin, the thick filament, is composed of a filamentous tail and a globular head region. The myosin head contains the actin binding site and the catalytic site for ATP hydrolysis, which drives the muscle contraction. Actin is the major contractile protein found in the thin filament. It has two forms, namely the monomeric $(\mathrm{G})$ form and the polymeric $(\mathrm{F})$ form, composed of individual $\mathrm{G}$ actin monomers. F-actin forms the backbone of the thin filament. Each monomer of G-actin within the F-actin has two myosin binding sites. The interaction between the myosin globular head and the actin unit in the presence of ATP results in crossbridge formation and sarcomere shortening. Tropomyosin is another protein found in the thin filament. It lies on either side of actin, thus adding rigidity to the thin filament. Tropomyosin influences actin-myosin cross bridge formation by physically interdigitating between the actin-myosin cleft (Katz, 1992). The troponin complex, also present in the thin filament is composed of three proteins namely troponin T, I, and C. Troponin regulates the extent of crossbridge formation and contributes to the structural integrity of the sarcomere. Troponin $\mathrm{T}$ binds the troponin complex to tropomyosin and anchors the complex to the thin filament. Normally, phosphorylated troponin I weakens the affinity of troponin $\mathrm{C}$ for $\mathrm{Ca}^{2+}$. The binding of $\mathrm{Ca}^{2+}$ to troponin $\mathrm{C}$ results in a conformational change of the complex, which exposes the actin /myosin binding cleft, 
promoting subsequent actin-myosin interaction, thus initiating cross bridge formation and muscle contraction.

Muscle relaxation depends upon the reduction of cytosolic calcium levels. This is realized mainly by the $\mathrm{SR} \mathrm{Ca}^{2+}$ pump which transports $\mathrm{Ca}^{2+}$ back to the sarcoplasmic reticulum in an ATP dependent manner. The sarcolemmal $\mathrm{Ca}^{2+}$-ATPase also removes a significant portion of $\mathrm{Ca}^{2+}$. Additional $\mathrm{Ca}^{2+}$ binding proteins like calmodulin and calsequestrin are also important. The complex formed when calmodulin binds intracellular $\mathrm{Ca}$ activates the sarcolemmal $\mathrm{Ca}^{2+}$-ATPase to extrude cytosolic $\mathrm{Ca}^{2+}$ (Feher et al., 1990; Sheu et al., 1986). Calsequestrin binds Ca within the cardiac SR lumen where it is located (Katz et al., 1986; Feher et al., 1990), and is the major $\mathrm{Ca}^{2+}$ reservoir between events.

In the failing hearts, patients exhibit both systolic and diastolic dysfunction. This is brought about by, among other things, cell death (microinfarction and scar) (Knowlton et al., 1992), dysfunctional cardiac metabolism (inadequate energy supply) (Alpert et al., 1962), abnormalities in cytoskeleton and contractile proteins (Unverferth and Lee, 1988), alteration in myocyte excitation-contraction coupling (Limas et al., 1987), dysfunctional myocyte signal transduction (Mitchell et al., 1995) and altered intracellular calcium transport and regulation. Of the various mechanisms stated above, intracellular calcium transport and regulation is the most dynamic and potentially reversible, thus the most treatable. Therefore, understanding the mechanism of calcium transport and its regulation is an important step towards finding a solution to heart disease. 


\section{$\mathrm{Ca}^{2+}$ ATPase}

The sarco(endo)plasmic reticulum $\mathrm{Ca}^{2+}$ - ATPases (SERCA) are $110 \mathrm{kDa}$, P-type ATPases that are responsible for the movement of $\mathrm{Ca}^{2+}$ from the cytosol to the lumen of the sarcoplasmic reticulum (SR). They are called P-type ATPases because they have an aspartate residue, within a DKTG consensus sequence that is phosphorylated by ATP during catalysis. The $\mathrm{Ca}^{2+}$ ATPase of muscle sarcoplasmic or endoplasmic reticulum consist of a single polypeptide chain, unlike other ATPases, which exist as $\alpha, \beta$ heterodimers $\mathrm{Na}^{+} / \mathrm{K}^{+}$ATPase. The SERCA pumps are coded for by 3 genes, named SERCA 1, 2 and 3. SERCA 1 is expressed mainly in fast twitch skeletal muscle. SERCA 2 consist of two isoforms, SERCA2a which is expressed in slow-twitch, cardiac and smooth muscle while SERCA2b has non-muscle distribution, including the brain. SERCA3 has a wide tissue distribution.

The amino acid sequences of most P-type ATPases have been known for some time and extensive mutational studies have been carried out to identify amino acids that are critical for ion transport. As shown in Figure 2 below, the $\mathrm{Ca}^{2+}-\mathrm{ATPase}$ consists of three globular cytoplasmic domains connected by helical stalk segments to ten transmembrane $\alpha$-helices (M1-M10). The first domain is a 125-residue loop connected to stalk regions $\mathrm{S} 2$ and $\mathrm{S} 3$, known as the activator domain. Next there is the phosphorylation domain, which is connected to stalk regions S4 and S5 and contains Asp-351, which becomes phosphorylated by ATP. Finally there is the nucleotide-binding domain (N domain) that is connected directly to the P domain. 


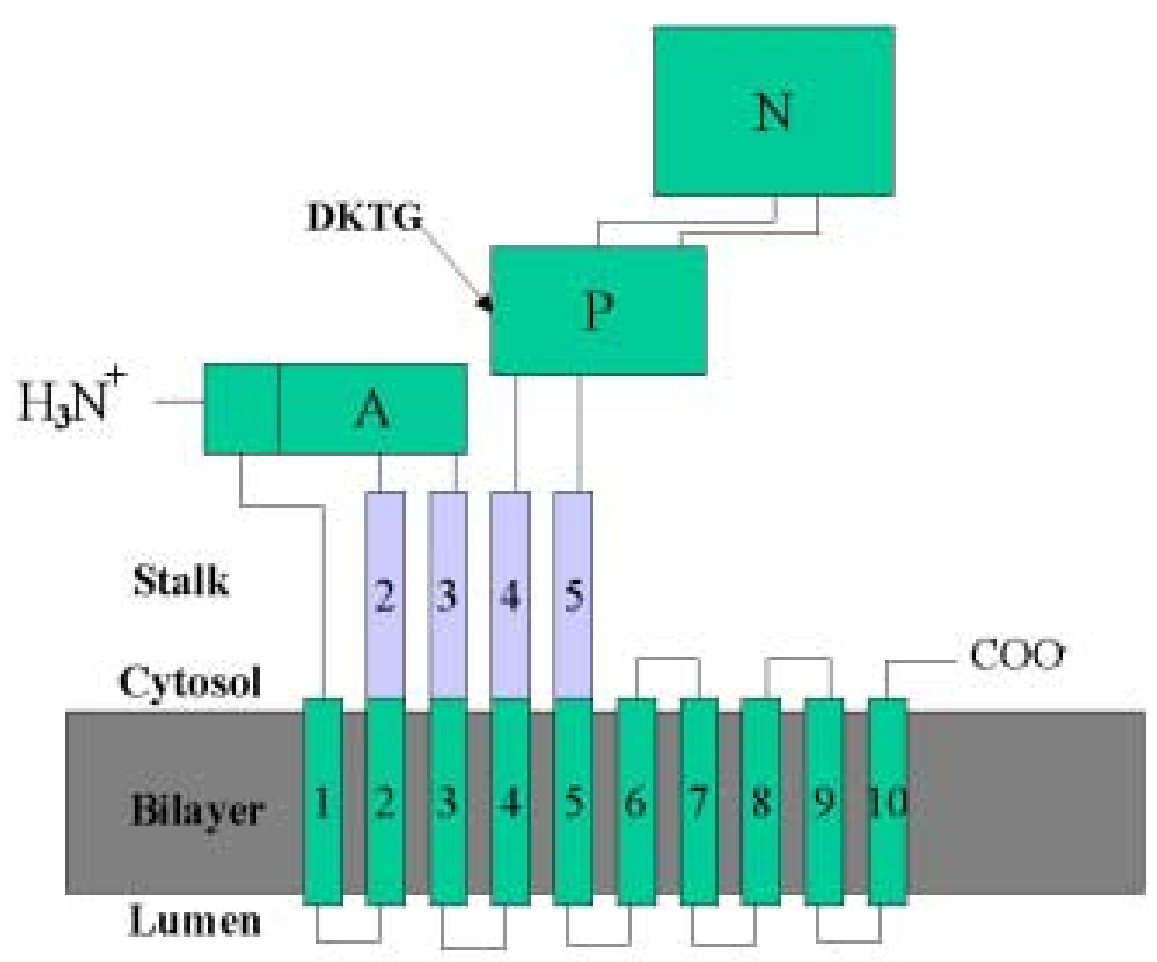

Figure 2: Secondary structure of the $\mathrm{Ca}^{2+}$-ATPase based on the crystal structure by Toyoshima et al (1998). The three cytoplasmic domains A (activation), $\mathrm{P}$ (phosphorylation) and $\mathrm{N}$ (nucleotide binding) are connected to the transmembrane $\alpha$ helical stalks (numbered 2-5 in accordance with the transmembrane $\alpha$-helix to which they are attached). The $\mathrm{N}$ domain forms an insert into the $\mathrm{P}$ domain. The location of the conserved phosphorylation motif is shown. 
The crystal structure of the SERCA1 $\mathrm{Ca}^{2+}$ - ATPase was reported in 2000. The ten transmembrane $\alpha$-helices, three cytoplasmic globular domains and the small loops on lumenal side were well resolved in structure (Figure 3). All the 994 amino acids in the crystal structure shown above were identified in the electron-density maps.

The structure of the $\mathrm{Ca}^{2+}$-ATPase crystallized in the presence of $\mathrm{Ca}^{2+}$ and the ATP analogue 2'3'-0-(2,4,6-trinitrophenyl)-adenosine monophosphate (TNP-AMP) shows TNP-AMP binding to the surface of the N domain, more than $25 \AA$ away from Asp 351 (Figure 3) (20) TNP-AMP is presumed to bind to the nucleotide binding site, since binding of analogues of TNP-AMP is competitive with binding of ATP. Because the adenosine moiety is known to bind around Lsy-515, Lys-492 and Phe-487 in the N domain, and because the phosphorylation site (Asp-351) on the P domain is distant by about $25 \AA$ in the crystal structure of the $\mathrm{Ca}^{2+}$ bound (E1) state (Toyoshima et al, 2000), very large motion of domain closure is necessary for the $\gamma$-phosphate of bound ATP to reach the phosphorylation site. This was recently confirmed by Toyoshima and coworker, who also showed the close interaction of the $\mathrm{N}, \mathrm{P}$ and A domains in the crystal structure of the $\mathrm{Ca}^{2+}$ free $\mathrm{Ca}^{2+}-$ ATPase.

\section{Mechanism of the $\mathrm{Ca}^{2+}$-ATPase}

The mechanism of the $\mathrm{Ca}^{2+}$-ATPase is usually discussed in terms of E1-E2 model developed from the Post-Albers scheme for the $\left(\mathrm{Na}^{+}, \mathrm{K}^{+}\right)$- ATPase, as shown in Scheme 1. The model proposes that the $\mathrm{Ca}^{2+}$-ATPase can exist in two distinct forms, E1 and E2. The E1 conformation contains two high affinity binding sites for $\mathrm{Ca}^{2+}$ that are exposed to the cytoplasm, whereas in the E2 conformation these two sites are transformed to low 


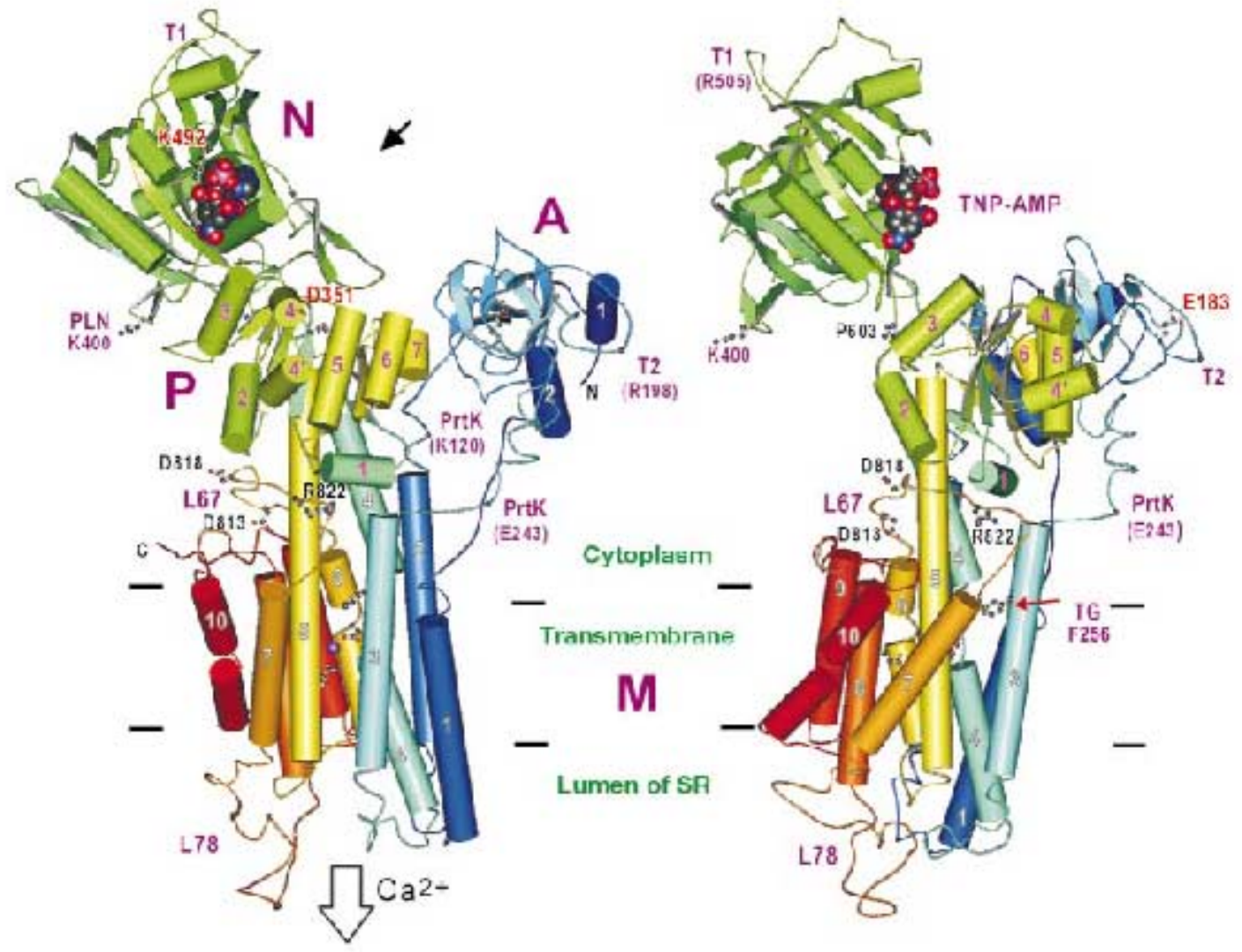




\section{Figure 3: Crystal structure of $\mathrm{Ca}^{2+}$ - ATPase}

In the figure, the cylinders represent $\alpha$-helices and arrows $\beta$-strand. The cylinders are not used for one-turn helices. The color changes gradually from N-terminal (blue) to Cterminal (red). The three cytoplasmic domains are labeled $\mathrm{A}, \mathrm{N}$ and $\mathrm{P}$. The transmembrane helices (M1-M10) and those in domains $\mathrm{A}$ and $\mathrm{P}$ are numbered. The orientation of the model shown above is such that Helix M5 is parallel to the plane of the paper. The model in the right panel is rotated by $50^{\circ}$ around M5, which is $60 \AA$ long and serves as a scale. Several key residues are shown in ball-and-stick, and 2'3'-0-(2,4,6trinitrophenyl)-Adenosinemonophosphate (TNP-AMP), which is a non-hydrolysable analog of ATP is shown. D351 is the residue of phosphorylation. Two purple spheres represent $\mathrm{Ca}^{2+}$ in the transmembrane binding site. The binding sites for phospholamban (PLN) and thapsigargin (TG) are marked. Also marked are the major digestion sites for Trypsin (T1 and $\mathrm{T} 2$ ) and proteinase $\mathrm{K}$ (PrtK). These digestion sites are important because they have been used to show changes in the cytoplasmic domain, which results in changes of accessibility of the enzyme to the cleavage sites. Reprinted with permission from Nature (Toyoshima, C., Nakasako, M., Nomura, H., Ogawa, H. 2000. Crystal structure of the calcium pump of sarcoplasmic reticulum at 2.6 Á resolution. Nature $\mathbf{4 0 5}$ : 647-654), www.nature.com/nature 


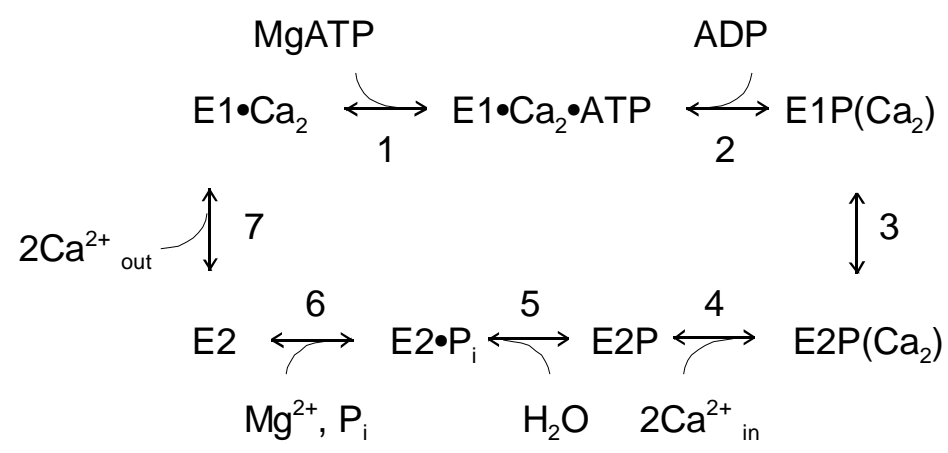

Scheme 1: E1/E2 Scheme for the CaATPase. Either ATP or $\mathrm{Ca}^{2+}$ can bind first to the E1 conformation of the CaATPase. A series of conformational changes leads to the intermidiate $\mathrm{E} 1 \cdot \mathrm{Ca}_{2} \cdot \mathrm{ATP}$ which undergoes phosphorylation to give $\mathrm{E} 1 \mathrm{P}\left(\mathrm{Ca}_{2}\right)$, which then undergoes further conformational changes to give $\mathrm{E} 2 \mathrm{P}\left(\mathrm{Ca}_{2}\right)$. This loses $\mathrm{Ca}^{2+}$ into the lumen and can be dephosphorylated to form E2, which can return to E1. 
affinity sites exposed to the lumen of the SR. This is referred to as the alternating site model. Following the binding of MgATP to the $\mathrm{Ca}^{2+}$-bound form of the ATPase (Step 1), the ATPase is phosphorylated at D351 forming E1P (Step 2), which undergoes a change in conformation to $\mathrm{E} 2 \mathrm{PCa}_{2}$ (Step 3), a state in which the two $\mathrm{Ca}^{2+}$ binding sites are of low affinity and inwardly facing. Following the loss of $\mathrm{Ca}^{2+}$ to the lumen of the SR (Step 4), the ATPase is dephosphorylated (Steps 5 and 6) and recycled to E1, which binds $\mathrm{Ca}^{2+}$

The phosphorylation and dephosphorylation events of the enzyme are reversible. The phosphorylated enzyme can react with ADP in the presence of $\mathrm{Ca}^{2+}$ to regenerate ATP. Also, incubation of the $\mathrm{Ca}^{2+}$ ATPase with phosphate (Pi) in the absence of cytoplasmic calcium, lead to phosphorylation of the ATPase to form E2P (Lacapere et al., 1981).

\section{Phosphorylation of the ATPase}

It has been shown using chemical labeling that the adenine and $\gamma$-phosphate moieties of ATP bind to separate domains on the ATPase, the N and P domains respectively. Analogues of ATP with reactive groups on the nucleotide ring invariably label residues in the $\mathrm{N}$ domain. ATP analogues block phosphorylation by ATP, but they do not affect smaller pseudo substrates like acetyl phosphate or Pi (Stokes and Green, 2000). However, if the reactive group is close to the $\gamma$-phosphate of ATP, then the enzyme residues labeled are in the P domain and neither ATP nor Pi can phosphorylate the modified ATPase.

The catalytically active $\mathrm{E} 1 \mathrm{Ca}_{2} \bullet \mathrm{ATP}$ conformation (Figure 3 ) can be produced by a pathway in which either $\mathrm{Ca}^{2+}$ or ATP binds first to the ATPase (Reinstein and Jencks, 
1993). However, the activated state can only be reached following the binding of both ATP and $\mathrm{Ca}^{2+}$. Binding of MgATP and activation of the enzyme is relatively slow in either pathway. This is because ATP binding is not simply an encounter process but, rather, involves a conformational change on the ATPase, triggered by ATP binding to the ATPase (Reinstein and Jencks, 1993).

\section{Phospholamban (PLB)}

Phospholamban is a small (52 residue) membrane-bound protein that modulates the activity of the $\mathrm{Ca}^{2+}$-ATPase in cardiac muscle SR.

Following the discovery of phospholamban, early work focused on its apparent role in regulation of calcium transport across the sarcoplasmic reticulum and sketching its complex protein structure. Other recent work has focused on the role of phospholamban in the regulation of myocardial function by catecholamines (Davis et al., 1990) and the role of phospholamban in skeletal and smooth muscle (Lompre et al., 1994).

Initially, phospholamban was implicated in the regulation of calcium transport across the cardiac SR by the correlation of cAMP-induced stimulation of calcium transport by the CaATPase, with the predominant phosphorylation of PLB by cAMPdependent protein kinase (Kirchberger et al, 1974). Because of its known role then as the principle substrate of cAMP-dependent protein kinase in cardiac SR vesicles, Tada et al (1975) named the protein phospholamban, meaning 'phosphate receptor'. The level of calcium transport stimulated by the cAMP-dependent mechanism was commensurate with the degree of phosphorylation of PLB (Tada and Katz, 1982). Phospholamban was also found to be the principle substrate of an endogenous myocardial 
calcium/calmodulin-dependent protein kinase. The phosphorylation of PLB by the cAMP-dependent protein kinase occur independently and additively (Imagawa et al, 1986), as does concomitant stimulation of calcium transport and ATPase activity (Kranias, 1985)

Structurally, PLB consists of a hydrophilic N-terminal domain (Met1 to Asn 30) linked to the hydrophobic C-terminal domain (Leu31 to Leu 52), which is likely to be a transmembrane $\alpha$-helix . PLB when unphosphorylated binds to the ATPase and inhibits it. Phosphorylation of PLB by $\mathrm{Ca}^{2+} /$ Calmodulin-dependent or cAMP-dependent protein kinase results in full ATPase activity, presumably as a result of uncoupling of PLB from the ATPase. The binding of PLB to the $\mathrm{Ca}^{2+}$-ATPase in cardiac SR reduces the apparent affinity of the ATPase for $\mathrm{Ca}^{2+}$. This has been determined from plots of $\mathrm{Ca}^{2+}$ uptake rate as a function of $\mathrm{Ca}^{2+}$ concentration. Other studies suggest that PLB controls $\mathrm{Ca}^{2+} \mathrm{ATPase}$ activity by decreasing by two fold the rate of phosphoenzyme decomposition. Froelich and Taylor $(1975,1976)$ have shown in kinetic studies that $\mathrm{Ca}^{2+}$ ATPase phosphoenzyme decomposition is a two-step process in which E2P is first hydrolyzed to E2.Pi followed by the release of Pi from the enzyme forming an E2 intermediate. PLB however, does not cause a decrease in ATPase activity at saturating concentrations of calcium.

PLB forms homopentamers that are stable in SDS-PAGE (Wegener and Jones, 1984). Spectroscopic analysis has verified that PLB is primarily oligomeric in lipid bilayer (Cornea et al., 1997). Simmerman et al (1996) showed by the use of site directed mutagenesis, the regions in PLB that are essential for pentameric stability. They also proposed that PLB pentamer is a left-handed coiled-coil, which is stabilized specifically by interactions between leucine residues 37, 44 and 51 and isoleucines 40 and 47 . Autry 
and Jones (1997) have shown that it is monomeric phospholamban that binds to and regulate the $\mathrm{Ca}^{2+}$-ATPase

Phospholamban has been purified (Inui et al., 1985; Jones et al., 1985), and its primary structure has been determined by cDNA cloning and sequencing (Fujii et al., 1987). It consists of five identical monomers (Wegener and Jones, 1984; Fujii et al., 1986), each of which contains two distinct domains, the hydrophilic N-terminal domain (domain I) and the hydrophobic C- terminal domain (domain II) (Fujii et al., 1986; Simmerman et al., 1986; Tada et al., 1988). The first 20 residues from the N-terminal (domain IA) are predicted to form an $\alpha$-helical structure containing serine 16 and threonine 17 phosphorylated by cAMP- and calmodulin-dependent protein kinases, respectively. The next 10 residues are less structured (domain IB). The last 22 residues form a hydrophobic transmembrane domain (domain 11). Recently, a direct proteinprotein interaction has been demonstrated between phospholamban and $\mathrm{Ca}^{2+}$-ATPase, which is diminished by phosphorylation of phospholamban (James et al., 1989).

The physiological role of phospholamban in cardiac health and disease has been the source of much speculation. Phospholamban clearly is a mediator in the regulation of myocardial function by catecholamines through the cyclic AMP cascade. This is consistent with the distribution of phospholamban in slow-twitch skeletal muscle as well as cardiac muscle which both exhibit cAMP-dependent stimulation of cardiac transport. Phospholamban however, has not been identified in fast-twitch skeletal muscle, which lack this response pathway (Jorgensen and Jones, 1986; Kimura et al., 1996). The physiological role of phospholamban has been demonstrated by recent work with cardiomyocytes and phospholamban knockout mice, and it was found that ablation of 
phospholamban greatly augments the intracellular $\mathrm{Ca}^{2+}$ transient and myocardial contractility and at the same time attenuates the cardiac response to $\beta$-adrenergic agents such as isoproterenol. Likewise, the overexpression of phospholamban or the expression of non-phosphorylatable phospholamban in transgenic mice lead to a variety of cardiac disease states, including cardiac hypertrophy and heart failure (Brittsan and Kranias, 2000).

\section{Overview of Thesis Research}

Despite considerable progress toward understanding the functional interaction of phospholamban with the Ca-ATPase, fundamental questions remain concerning the kinetic basis by which phospholamban inhibits the Ca-ATPase. The primary functional effect of phospholamban on the Ca-ATPase is to decrease the apparent $\mathrm{Ca}^{2+}$ affinity of the enzyme (see Figure 1, below). There have been many kinetics studies on the effects of phospholamban on the partial reactions of the Ca-ATPase cycle (Tada et al., 1975, 1979, 1980; Jones et al., 1978; Kranias et al., 1980; Sumida et al., 1980; Cantilina et al., 1993; Antipenko et al., 1997, 1999; Mahaney et al., 2000) designed to elucidate this effect. However, these studies have failed to provide a definitive mechanism by which phospholamban decreases the apparent $\mathrm{Ca}^{2+}$ affinity of the Ca-ATPase.

The most widely accepted view of the mechanistic basis for Ca-ATPase inhibition by phospholamban was reported by Cantilina et al. (1993), who proposed that phospholamban decreases by ten fold the rate of $\mathrm{C} \mathrm{Ca}^{2+}$-dependent conformational change that activates the Ca-ATPase for ATP-dependent phosphoenzyme formation. In so doing, phospholamban makes the Ca-ATPase less sensitive to $\mathrm{Ca}^{2+}$, giving the 
appearance of a change in $\mathrm{Ca}^{2+}$ affinity. However, the effect of phospholamban on the $\mathrm{Ca}^{2+}$-dependent activation of the Ca-ATPase has not been tested quantitatively. To do this, one must first determine whether phospholamban affects the net activation energy of the Ca-ATPase during steady-state enzyme cycling. In light of a positive result, one can focus specifically on the activation energy of the $\mathrm{Ca}^{2+}$-dependent conformational transition that precedes Ca-ATPase phosphorylation by ATP.

The goal of this thesis research was to test the hypothesis that phospholamban increases the activation energy for steady-state enzyme cycling. To test this hypothesis, we have studied the effect of phospholamban on the temperature dependence of CaATPase steady-state activity and phosphoenzyme levels. These parameters were used to calculate the enzyme turnover number as a function of temperature, in order to determine the activation energy for steady-state enzyme cycling. For these studies, we have employed the baculovirus-insect cell expression system to produce samples containing the cardiac Ca-ATPase expressed in the absence (control) and presence of co-expressed phospholamban. An advantage of using this system was that it produced sufficient quantities of sample for detailed kinetics studies, while at the same time allowing us to examine the Ca-ATPase co-expressed alone versus Ca-ATPase co-expressed with phospholamban. The effect of phospholamban on Ca-ATPase turnover was explored further by using anti-phospholamban monoclonal antibody to uncouple phospholamban from the Ca-ATPase. In particular, we have pursued the following specific aims:

\footnotetext{
Aim 1: Determine the influence of phospholamban on the temperature-dependence of Ca-ATPase steady-state activity. For these studies, we utilized an NADH-based
} 
enzyme-coupled assay in a temperature-controlled UV-VIS spectrophotometer to determine if Ca-ATPase steady-state activity is affected by phospholamban.

\begin{abstract}
Aim 2: Determine the effect of phospholamban on Ca-ATPase pre-steady state phosphorylation kinetics. For these studies, we utilized ${ }^{32}$ P-ATP to measure steadystate Ca-ATPase phosphorylation levels, as affected by phospholamban.
\end{abstract}

\begin{abstract}
Aim 3: Combine the results of Aims 1 and 2 to determine the effect of phospholamban on Ca-ATPase activation energy. Ca-ATPase velocity (nmol ATP split / mg protein / sec) divided by the phosphoenzyme level (nmol EP / mg protein) provided the Ca-ATPase turnover number, $\mathrm{k}_{\mathrm{cat}}$, as a function of temperature. An Arrhenius plot of $\mathrm{k}_{\text {cat }}$ versus $1 / \mathrm{T}$ provided the activation energy for the Ca-ATPase in the absence and presence of phospholamban.
\end{abstract}

The results of these studies indicated that phospholamban increased the activation energy for steady-state Ca-ATPase activity. Based on this positive result, a more detailed analysis of the activation energy of individual steps in the Ca-ATPase cycle is warranted. The results of this study, and the studies that will follow this project, should provide new insights into the mechanisms of catalysis and regulation of calcium transport in cardiac muscle SR, which is a critical step toward understanding cardiac performance and malfunction. 


\section{Chapter 2: Methods}

\section{Reagents and Solutions.}

${ }^{125}$ I-Protein A and $\left[\gamma^{32} \mathrm{P}\right] \mathrm{ATP}$ were obtained from ICN. Other reagents were obtained either from Sigma or Fisher Scientific and were of the highest purity available. The antibodies used in this study were a gift from Dr. Larry Jones, Indiana University School of Medicine.

\section{Protein Expression and Isolation.}

Recombinant baculoviruses containing cDNA inserts for either canine cardiac Ca-ATPase (SERCA2a) or canine phospholamban were prepared by Jamie Huffman in our laboratory using the Baculogold Baculovirus Expression Kit from PharMingen. Wild type canine SERCA2a and wild type canine phospholamban were expressed in High-Five insect cells grown in suspension $\left(1.5-2.0 \times 10^{6}\right.$ cells $\left./ \mathrm{ml}\right)$ at $27^{\circ} \mathrm{C}$ in serum free medium (Invitrogen). Microsomes were isolated from insect cells harvested 48 hours after infection with baculoviruses. For expression of Ca-ATPase alone, a multiplicity of infection (MOI) of 10 (viruses/cell) was used. For co-expression of Ca-ATPase with phospholamban, a MOI of 15 was used for SERCA2a and 5 for phospholamban (WT). Virus-infected High-Five cells in $600 \mathrm{ml}$ suspension $\left(1 \times 10^{9}\right.$ cells $)$ were sedimented and washed twice with ice cold 1x PBS, by centrifuging for 10 minutes at $1500 \mathrm{rpm}$ and $25^{\circ} \mathrm{C}$ in an IEC GP8R refrigerated centrifuge. The washed cells were resuspended in $60 \mathrm{ml}$ of ice cold $10 \mathrm{mM} \mathrm{NaHCO}_{3}$ and $0.2 \mathrm{mM} \mathrm{CaCl}_{2}$, followed by the addition of $60 \mathrm{ml}$ of ice 
cold $500 \mathrm{mM}$ Sucrose, $300 \mathrm{mM} \mathrm{KCl,} 6 \mathrm{mM} \mathrm{MgCl}_{2}$, and $60 \mathrm{mM}$ histidine. Both buffers contained $10 \mu \mathrm{g} / \mathrm{ml}$ aprotinin, $2 \mu \mathrm{g} / \mathrm{ml}$ leupeptin, $1 \mu \mathrm{g} / \mathrm{ml}$ pepstatin $\mathrm{A}$, and $0.1 \mathrm{mM}$ pefabloc. The cells were transferred to a cold room $\left(4^{\circ} \mathrm{C}\right)$ and homogenized for 90 seconds with a Brinkman polytron (full speed) and placed back on ice. The homogenate was then centrifuged for 20 minutes at $3000 \mathrm{rpm}$ and $4^{\circ} \mathrm{C}$ in a Sorvall SS-34 rotor. The supernatant was collected, and $30 \mathrm{ml}$ of $3 \mathrm{M} \mathrm{KCl}$ was added to it and it was centrifuged for 20 minutes at $9000 \mathrm{rpm}$ and $4^{\circ} \mathrm{C}$ in a Sorvall SS-34 rotor. The supernatant was collected and the final High-five insect cell microsomes were pelleted by centrifugation for 38 minutes at $26000 \mathrm{rpm}$ and $4^{\circ} \mathrm{C}$ in a Beckman Ti-45 rotor. Pellets were resuspended in $5 \mathrm{ml}$ of buffer containing $250 \mathrm{mM}$ sucrose, $30 \mathrm{mM}$ histidine (pH 7.4) and stored in small aliquots at $-50^{\circ} \mathrm{C}$. Protein concentrations were determined by the method of Lowry et al. (1951), using BSA as a standard.

\section{Electrophoresis and Immunoblotting}

Prior to electrophoresis, samples were solubilized at $37^{\circ} \mathrm{C}$ for 5 minutes in a dissociation medium that consisted of $62.5 \mathrm{mM}$ Tris ( $\mathrm{pH} 6.8), 5 \%$ glycerol, $5 \%$ sodium dodecyl sulfate (SDS), $40 \mathrm{mM}$ dithiothreitol, and $0.0025 \%$ bromophenol blue. SDSPAGE gel electrophoresis was conducted by the method of Porzio and Pearson (1977), using $8 \%$ polyacrylamide (BioRad Mini-Protean II system). Kaleidoscope prestained molecular weight markers (BioRad) were used as standards. Gels were stained using gelcode blue stain reagent (Pierce), or proteins were transferred (BioRad Mini-Trans blot system) to nitrocellulose (SERCA2a blots) or PVDF (PLB blots) membranes (BioRad) for immunoblotting. The transfer protocol was carried out according to instructions 
provided by the manufacturer, with the exception that methanol was omitted from the transfer buffer. Mahaney et al. (2000) reported that methanol in the transfer medium decreased SERCA2a and PLB protein transfer. The nitrocellulose membranes were probed with an anti-SERCA2a monoclonal antibody 2A7-A1 for detection of SERCA2a. The PVDF membranes were probed with anti-phospholamban monoclonal antibody 2D12 for detection of phospholamban (Movsesian et al., 1994). Antibody binding was visualized by using $\left[{ }^{125} \mathrm{I}\right]$ - protein $\mathrm{A}$ and quantitated using Molecular Dynamics Phosphoimager SI. Cardiac SR was used as a standard since it is known to contain $36 \%$ SERCA2a by weight and 2\% PLB by weight, based on quantitative immunoblots using purified Ca-ATPase and phospholamban as standards (Waggoner and Mahaney, unpublished results). Typically, our insect cell microsomes contained about 12-15\% SERCA2a and $1-1.5 \%$ phospholamban per total protein by weight. Converting to moles of SERCA2a $\left(\mathrm{M}_{\mathrm{r}}=110,000 \mathrm{~g} / \mathrm{mol}\right)$ and phospholamban $\left(\mathrm{M}_{\mathrm{r}}=6,080 \mathrm{~g} / \mathrm{mol}\right)$ per $\mathrm{mg}$ of microsomal protein, these results indicated a molar ratio of 1:2 SERCA2a to PLB, similar to that found in native cardiac SR (Mahaney et al., 2000).

\section{Ca-ATPase Activity Assays.}

$\left[\mathrm{Ca}^{2+}\right]$-dependent ATPase activity of SERCA2a in the High-Five insect cell microsomes was measured by two different methods. The $\left[\mathrm{Ca}^{2+}\right]$-dependence of CaATPase activity was measured colorimetrically at $37^{\circ} \mathrm{C}$, using a malachite greenammonium molybdate assay (Lanzetta et al., 1979; Mahaney et al., 1995). SERCA2a incubation tubes contained $0.05 \mathrm{mg}$ microsomal protein per ml protein in $50 \mathrm{mM} \mathrm{3}-[\mathrm{N}-$ morpholino]propanesulfonic acid (MOPS) (pH 7.0), $3 \mathrm{mM} \mathrm{MgCl}_{2}, 100 \mathrm{mM} \mathrm{KCl}, 1 \mathrm{mM}$ EGTA, and 0-1.0 $\mathrm{mM} \mathrm{CaCl}_{2}$ to give the desired ionized $\left[\mathrm{Ca}^{2+}\right]$, as previously determined 
(Autry and Jones, 1997). To start the ATPase reaction, $5 \mathrm{mM} \mathrm{MgATP}$ was added to the incubation tube. After 10 minutes of reaction at $37^{\circ} \mathrm{C}$, a $50 \mu \mathrm{l}$ aliquot of the incubation mix was transferred into an assay tube containing $1.6 \mathrm{ml}$ malachite green-ammonium molybdate reagent at room temperature. After 30 seconds the reaction was quenched by the addition of $200 \mu \mathrm{l}$ of $34 \%$ sodium citrate into the assay tube. For the determination of phosphate, a standard curve was constructed using aliquots from a $0.4 \mathrm{mM}$ phosphate standard solution, which was assayed in a similar fashion as above. After 30 minutes of color development, the absorbance was measured at $660 \mathrm{~nm} .\left[\mathrm{Ca}^{2+}\right]$-dependent ATPase activity data were fit by the Hill equation using the program KFIT written by N. C. Millar:

$$
v=\frac{V_{\max }}{1+10^{n(K-[C a])}}
$$

where $\mathrm{v}$ is the enzyme velocity at any given $\left[\mathrm{Ca}^{2+}\right], \mathrm{V}_{\max }$ is the maximum velocity at saturating $\left[\mathrm{Ca}^{2+}\right], \mathrm{n}$ is the Hill coefficient, $\mathrm{K}$ is the $\left[\mathrm{Ca}^{2+}\right]$ required for half-maximal velocity, and $\left[\mathrm{Ca}^{2+}\right]$ is the ionized $\mathrm{Ca}^{2+}$ level for each particular assay. The best fits of the data were chosen on the basis of optimization of the determination coefficient, $\mathrm{R}^{2}$, and/or minimization of the sum-of-squares error, $\Pi^{2}$.

For the Arrhenius analyses, Ca-ATPase activity of the microsomal samples was measured spectrophotometrically with a continuous ATPase assay using an ATPregenerating system (Madden et al., 1979). Assays were performed in $1 \mathrm{ml}$ of buffer containing $50 \mathrm{mM}$ MOPS (pH 7.0), $3 \mathrm{mM} \mathrm{MgCl} 2,100 \mathrm{mM} \mathrm{KCl}, 1 \mathrm{mM}$ EGTA, and 0.5 $\mathrm{mM} \mathrm{CaCl}$, which provided a $\left[\mathrm{Ca}^{2+}\right]_{\text {free }}$ of $0.270 \mathrm{nM}$, as previously determined (Autry and 
Jones, 1997). In addition, the assay cuvettes contained $0.2 \mathrm{mM}$ phosphoenolpyruvate, 0.2 mM NADH, 8 units pyruvate kinase, 20 units lactate dehydrogenase, which served as an ATP regenerating system and provided a means to monitor the progress of the assay. For each assay, $50 \mu \mathrm{g}$ SR protein was added to the assay cuvette pre-equilibrated at the desired experimental temperature and incubated for 5 minutes. To start the assay, $5 \mathrm{mM} \mathrm{MgATP}$ was added to the cuvette, and the rate of change of absorbance of NADH at $340 \mathrm{~nm}$ was recorded to estimate the rate of ATP hydrolysis.

For each activity assay, the microsomal samples were permeabilized with the $\mathrm{Ca}^{2+}$ ionophore (20 $\mu \mathrm{g}$ per $\mathrm{mg}$ total protein) prior to the start of the assay to allow Ca-ATPase activity to be measured in the absence of a $\mathrm{Ca}^{2+}$ gradient. To test the effect of phospholamban on Ca-ATPase activity, SERCA2a + PLB samples were incubated for 20 minutes without or with affinity purified anti-phospholamban monoclonal antibody 2D12 (courtesy L. Jones), at an antibody-to-protein weight ratio of 1:1 (Autry and Jones, 1997).

\section{Ca-ATPase Phosphoenzyme Levels.}

Ca-ATPase phosphoenzyme formation experiments were carried out at the indicated temperatures using a circulating water bath to control the reaction temperature to within $\pm 1^{\circ} \mathrm{C}$. Prior to phosphoenzyme formation, the microsomal samples were permeablized by the addition of calcium ionophore A23187 (20 $\mu \mathrm{g} / \mathrm{mg}$ protein). Next, $0.25 \mathrm{ml}$ of a solution containing $0.2 \mathrm{mg}$ microsomes $/ \mathrm{ml}$ in $50 \mathrm{mM}$ MOPS (pH 7.0), $3 \mathrm{mM}$ $\mathrm{MgCl}_{2}, 100 \mathrm{mM} \mathrm{KCl}, 1 \mathrm{mM}$ EGTA and $0.5 \mathrm{mM} \mathrm{CaCl}_{2}$, which provided a $\left[\mathrm{Ca}^{2+}\right]_{\text {free }}$ of $0.270 \mathrm{nM}$, as described above, was placed in a $7 \mathrm{ml}$ glass scintillation vial (VWR) and set in the water bath. To initiate phosphoenzyme formation, $0.25 \mathrm{ml}$ of a solution containing 
$50 \mathrm{mM}$ MOPS (pH 7.0), $3 \mathrm{mM} \mathrm{MgCl} 2,100 \mathrm{mM} \mathrm{KCl}, 1 \mathrm{mM} \mathrm{EGTA}, 0.5 \mathrm{mM} \mathrm{CaCl}_{2}$, and $20 \mu \mathrm{M}\left[\gamma_{-}{ }^{32} \mathrm{P}\right] \mathrm{ATP}(20,000 \mathrm{cpm} / \mathrm{nmol})$ was rapidly added (less than $\left.1 \mathrm{sec}\right)$ to the microsome-containing vial with vigorous vortexing. The final conditions following mixing were $0.1 \mathrm{mg} / \mathrm{ml}$ microsomes, $10 \mu \mathrm{M}\left[\gamma_{-}{ }^{32} \mathrm{P}\right] \mathrm{ATP}, 50 \mathrm{mM}$ MOPS (pH 7.0), $3 \mathrm{mM}$ $\mathrm{MgCl}_{2}, 100 \mathrm{mM} \mathrm{KCl}, 1 \mathrm{mM}$ EGTA, and $0.5 \mathrm{mM} \mathrm{CaCl} 2\left(\left[\mathrm{Ca}^{2+}\right]_{\text {free }}=270 \mathrm{nM}\right)$. The reaction was allowed to proceed for $15 \mathrm{sec}$ before quenching by the rapid addition of 0.5 $\mathrm{ml}$ of ice-cold $9 \%$ perchloric acid $+6 \mathrm{mM} \mathrm{H}_{3} \mathrm{PO}_{4}$, followed by vigorous vortexing. After quenching, the reaction tubes were placed on ice. Blank tubes were prepared by first adding $0.5 \mathrm{ml}$ of quench solution to the $0.25 \mathrm{ml}$ microsome-containing solution, vortexing vigorously, then adding $0.25 \mathrm{ml}$ of the ATP-containing solution. A $25 \mu 1$ aliquot of $10 \mathrm{mg} / \mathrm{ml}$ bovine serum albumin was added to each quenched sample to act as carrier protein during the processing of the sample vials. The quenched samples were pelleted by centrifugation for $10 \mathrm{~min}$ at $3000 \mathrm{x} \mathrm{g}, 4$ degrees $\mathrm{C}$ in an IEC GP8R refrigerated centrifuge, and then washed three times by similar centrifugation using an ice-cold solution of $5 \%$ trichloroacetic acid, $6 \%$ polyphosphoric acid, $4 \mathrm{mM} \mathrm{H}_{3} \mathrm{PO}_{4}$, and $5 \mathrm{mM}$ non-radioactive ATP. Pellet recovery following washing was greater than $95 \%$, determined by protein assay. The final pellets were dissolved in $5 \mathrm{ml} 1 \mathrm{~N} \mathrm{NaOH}$ and the ${ }^{32} \mathrm{P}$-phosphoenzyme was assayed by counting the Cerenkov radiation. 


\section{Chapter 3: Results}

\section{Protein Expression, Characterization and Assay.}

For this study, canine cardiac Ca-ATPase (the SERCA2a isoform) and canine phospholamban were expressed in High Five insect cells using recombinant baculoviruses (Autry and Jones, 1997) and isolated as High Five insect cell microsomes. The $\mathrm{Ca}^{2+}$-ATPase was expressed either alone $\left(\mathrm{Ca}^{2+}\right.$-ATPase only) or co-expressed with wild-type phospholamban (WT-PLB). The amount of $\mathrm{Ca}^{2+}$-ATPase and phospholamban in the insect cell microsome samples was determined by immunoblotting (Figure 4), using the $\mathrm{Ca}^{2+}$-ATPase and phospholamban in native cardiac SR vesicles as standards. Waggoner and Mahaney (unpublished results) have used quantitative immunoblotting techniques to determine the Ca-ATPase and phospholamban content of the cardiac SR vesicles, which are $36 \%$ and $2 \%$ by weight total protein, respectively. Based on phosphorimage analysis of the immunoblot shown in Figure 4, our insect cell microsomes contained about $15 \%$ Ca-ATPase and $1.5 \%$ phospholamban per total protein by weight. Converting to moles of SERCA2a $\left(\mathrm{M}_{\mathrm{r}}=110,000 \mathrm{~g} / \mathrm{mol}\right)$ and phospholamban $\left(\mathrm{M}_{\mathrm{r}}=6,080 \mathrm{~g} / \mathrm{mol}\right)$ per $\mathrm{mg}$ of microsomal protein, these results indicated a molar ratio of 1:2 Ca-ATPase to PLB, similar to that found in native cardiac SR (Waggoner and Mahaney, unpublished results).

The ATPase activity of the expressed Ca-ATPase and the functional coupling between Ca-ATPase and phospholamban in the $\mathrm{Sf} 21$ cell microsome samples was assayed at $37^{\circ} \mathrm{C}$ at a series of $\left[\mathrm{Ca}^{2+}\right]_{\text {free }}$ in the presence and absence of anti- 
phospholamban monoclonal antibody 2D12, which reverses the inhibitory interaction between phospholamban and Ca-ATPase (Briggs et al., 1992; Sham et al., 1991). Each 


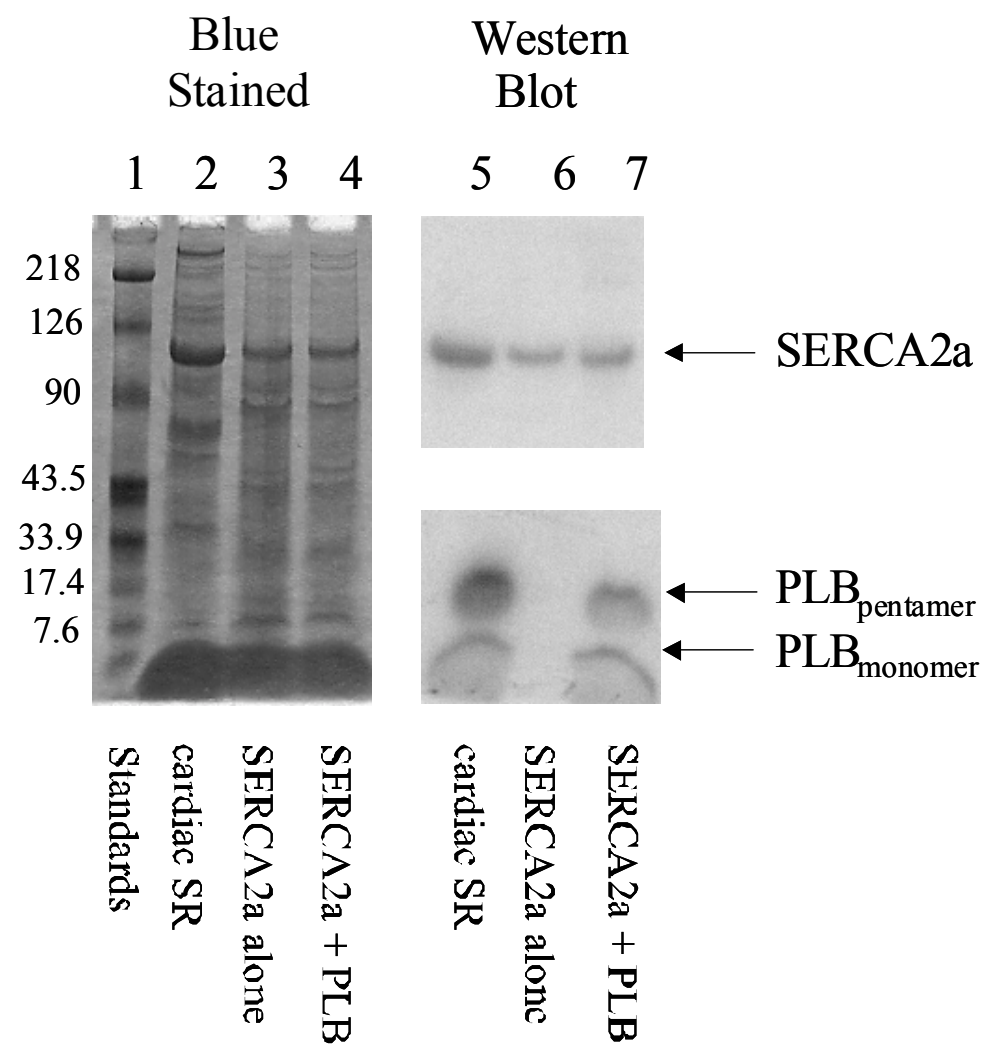


Figure 4: SDS-PAGE and immunoblot of Ca-ATPase and phospholamban in cardiac SR vesicles and High Five insect cell microsomes. Left: Coomassie bluestained SDS gel (10 $\mu \mathrm{g}$ protein per lane) showing cardiac SR vesicles (lane 2$)$, insect cell microsomes containing SERCA2a alone (lane 3) or SERCA2a + phospholamban (lane 4) Right: corresponding immunoblot of the SDS gel (left) showing cardiac SR vesicles (lane 5), insect cell microsomes containing SERCA2a alone (lane 6) or SERCA2a + phospholamban (lane 7). PLB $_{\text {pentamer }}$ denotes pentameric phospholamban and PLB $_{\text {monomer }}$ denotes monomeric phospholamban. The blots utilized SERCA2a antibody 2A7-A1 (top) or phospholamban antibody $2 \mathrm{D} 12$ (bottom), and were developed with ${ }^{125}$ I-protein A. The immunoblots were quantified by PhosphorImage analysis. The cardiac SR sample was included as a means to estimate the amount of SERCA2a in the expressed samples. Given that cardiac SR contains 30\% SERCA2a and 1.5\% phospholamban by weight, the two expressed samples contained approximately $14 \%$ SERCA2a and $0.7 \%$ phospholamban by weight by comparison. 
expressed Ca-ATPase sample displayed the usual sigmoidal $\left[\mathrm{Ca}^{2+}\right]$-dependence, and the maximum steady-state activity $\left(\mathrm{V}_{\max }\right)$ of the various samples was similar (approximately $0.4-0.5 \mu \mathrm{mol} / \mathrm{mg}$ total protein $/ \mathrm{min}$ ) when measured at saturating ionized $\left[\mathrm{Ca}^{2+}\right]$ (Figure 5). Treatment of the expressed samples with monoclonal antibody produced no effect on the maximal activity of the sample. Lack of effect of the monoclonal antibody on the CaATPase $\mathrm{V}_{\max }$ in cardiac SR vesicles and Ca-ATPase expressed in insect cells is well known (Autry and Jones, 1997; Mahaney et al., 2000).

Ca-ATPase expressed without phospholamban had a high apparent $\mathrm{Ca}^{2+}$ affinity $\left(\mathrm{K}_{\mathrm{ca}}=200 \mathrm{nM}\right)$, which was unaffected by treatment of the sample with phospholamban monoclonal antibody. When coexpressed with wild-type phospholamban, the Ca-ATPase activity curve was shifted to the right relative to that of Ca-ATPase expressed alone, resulting in an increase in $\mathrm{K}_{\mathrm{Ca}}$ to $420 \mathrm{nM}$. Treatment with anti-phospholamban antibody $2 \mathrm{D} 12$ shifted the $\mathrm{Ca}^{2+}$ activation curve to the left, resulting in a decreased $\mathrm{K}_{\mathrm{Ca}}$ value similar to that obtained for Ca-ATPase in the absence of phospholamban. The results show that phospholamban was functionally coupled to Ca-ATPase in the expressed samples.

\section{Effect of Phospholamban on the Temperature-dependence of Ca-ATPase Activity.}

To determine the effect of phospholamban on Ca-ATPase activation energy, we measured Ca-ATPase activity and phosphoenzyme (EP) levels at a series of temperatures between $5^{\circ} \mathrm{C}$ and $40^{\circ} \mathrm{C}$ using insect cell microsomes containing Ca-ATPase expressed alone (Ca-ATPase only) and in the presence of phospholamban (Ca-ATPase + PLB). The effect of phospholamban on Ca-ATPase activation energy was explored further using 


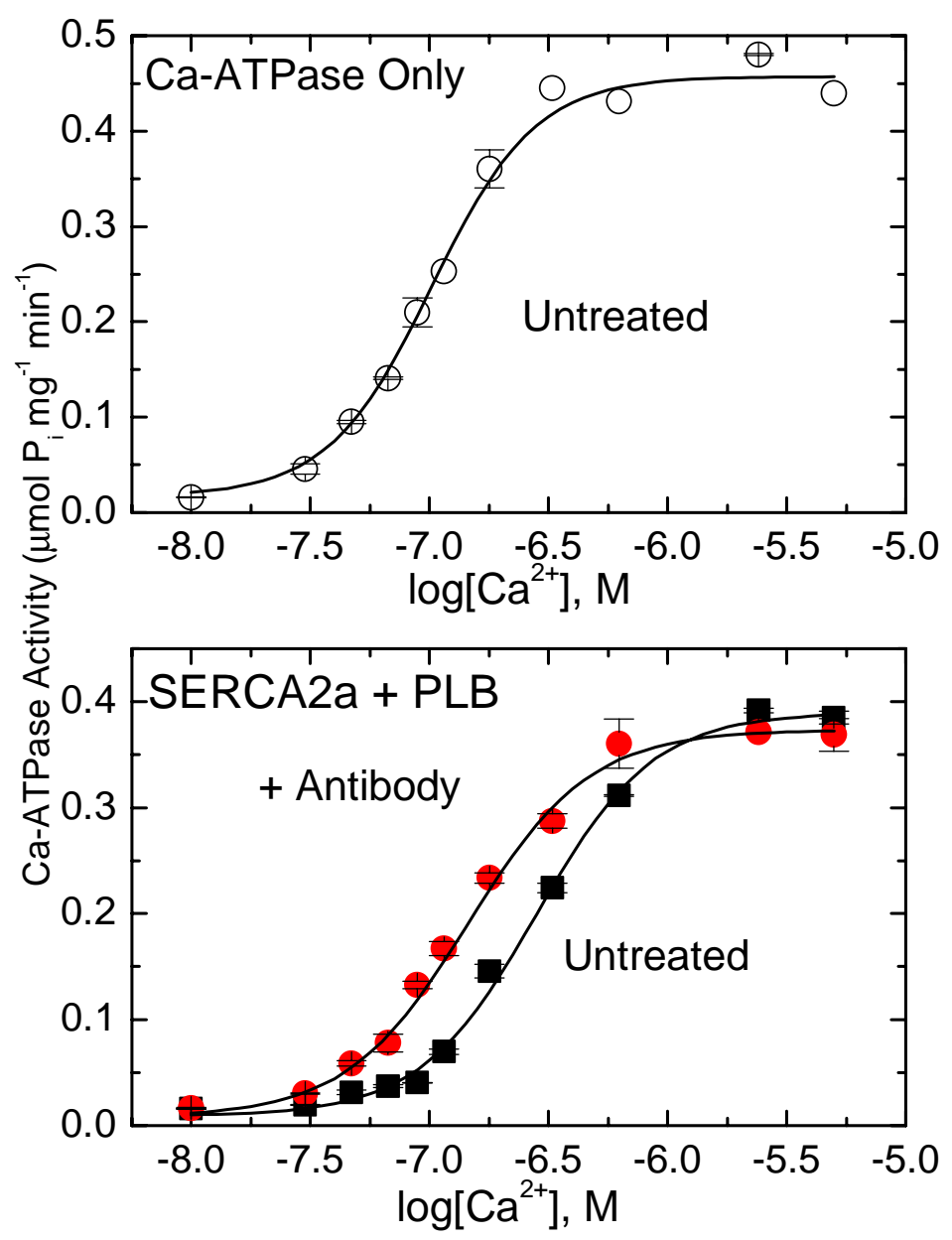


Figure 5: Effect of phospholamban on Ca-ATPase activity at $37^{\circ} \mathrm{C}$. Ca-ATPase activity was measured colorimetically as described in Chapter 2 (Methods), using Hive Five insect cell microsomes containing Ca-ATPase expressed alone (Ca-ATPase only, open squares, top panel) or Ca-ATPase coexpressed with phospholamban (Ca-ATPase + PLB, filled symbols, bottom panel). The Ca-ATPase samples exhibited a sigmoidal dependence on $\left[\mathrm{Ca}^{2+}\right]$, which was characterized in terms of maximum activity (Vmax) and the $\left[\mathrm{Ca}^{2+}\right]$ required for half maximal activity (denoted $\mathrm{K}_{\mathrm{Ca}}$ ). The $\mathrm{K}_{0.5}$ for Ca-ATPase in the presence of phospholamban (filled squares, bottom panel) was approximately 420 $\mathrm{nM}$, compared to $200 \mathrm{nM}$ for Ca-ATPase alone (empty squares, top panel) or $220 \mathrm{nM}$ for Ca-ATPase + phospholamban treated with a monoclonal antibody to uncouple phospholamban from the Ca-ATPase (filled circles, bottom panel). Phospholamban had no effect on $\mathrm{V}_{\max }$ for the Ca-ATPase + phospholamban sample. The results confirm that phospholamban inhibits Ca-ATPase by decreasing the $\mathrm{Ca}^{2+}$ sensitivity of the enzyme. 
an anti-phospholamban monoclonal antibody to uncouple phospholamban from the CaATPase. These measurements were conducted at an ionized $\mathrm{Ca}^{2+}$ level of $270 \mathrm{nM}$, which is near the $\mathrm{K}_{0.5}$ value for the Ca-ATPase in the absence and presence of phospholamban (Figure 5).

As shown in Figure 6, the Ca-ATPase activity of the microsomal samples increased with increasing temperature. The temperature dependence was similar for samples containing Ca-ATPase expressed alone (Figure 6, top) or Ca-ATPase coexpressed with phospholamban (Figure 6, bottom). At higher temperatures $\left(25-40^{\circ} \mathrm{C}\right)$, phospholamban decreased Ca-ATPase activity by about $20 \%$ relative to samples treated with 2D12 to uncouple phospholamban from the Ca-ATPase. At lower temperatures (5$20^{\circ} \mathrm{C}$ ), however, there was no significant difference between untreated and antibodytreated samples. The activity of the antibody-treated Ca-ATPase + phospholamban sample was similar to that of the Ca-ATPase only sample at each temperature, ensuring that the antibody successfully uncoupled phospholamban from the Ca-ATPase at all temperatures studied.

\section{Effect of Phospholamban on the Temperature-dependence of Ca-ATPase EP formation.}

During the Ca-ATPase reaction cycle, the enzyme is phosphorylated by ATP, which drives $\mathrm{Ca}^{2+}$ translocation. Using radio labeled ATP, one can determine the amount of phosphorylated Ca-ATPase during steady state enzyme cycling (Methods). In effect, the EP level provides information about the catalytic site density of the enzyme, since the fraction of the enzymes phosphorylated during steady-state cycling gives rise to product 

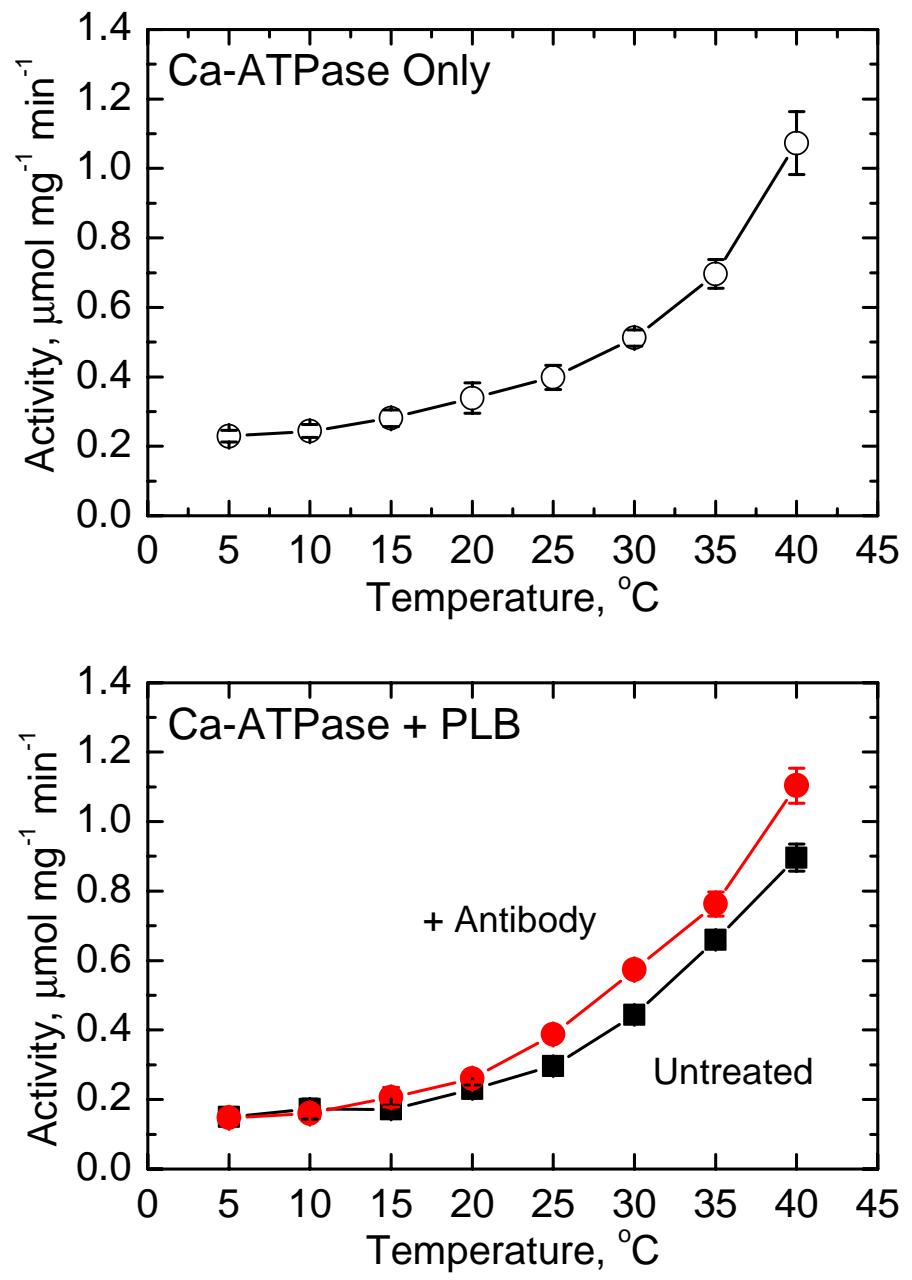
Figure 6: Effect of phospholamban on the temperature dependence of Ca-ATPase activity. Ca-ATPase activity was measured at $\left[\mathrm{Ca}^{2+}\right]_{\text {free }}=270 \mathrm{nM}$ at the indicated temperatures with a coupled enzyme assay as described in Chapter 2 (Methods), using Hive Five insect cell microsomes containing Ca-ATPase only or Ca-ATPase + phospholamban (Ca-ATPase $+\mathrm{PLB})$. The $\left[\mathrm{Ca}^{2+}\right]_{\text {free }}$ was selected to be near the $\mathrm{K}_{0.5}$ value for both sample types, where phospholamban has significant effects on Ca-ATPase activity (Figure 2). This experiment was carried out using different (and more active) sample preparations than those shown in Figure 2, which is reflected in differences in the $37{ }^{\circ} \mathrm{C}$ activities between the two figures. The symbols and sample conditions correspond to those defined in Figure 5. 
release and enzyme turnover. Therefore, the steady-state phosphoenzyme (EP) level of each microsomal Ca-ATPase sample was measured as a function of temperature at 270 nM ionized $\mathrm{Ca}^{2+}$ using $\left[\gamma_{-}{ }^{32} \mathrm{P}\right] \mathrm{ATP}$. Because temperature was not expected to affect the catalytic site density of the Ca-ATPase samples (Mahaney et al., 1995), we focused our

measurements on three temperatures, $5^{\circ} \mathrm{C}, 20^{\circ} \mathrm{C}$ and $40^{\circ} \mathrm{C}$. As expected, a similar value of EP was obtained at each temperature studied for each individual sample type. For the Ca-ATPase + phospholamban sample, the steady EP level was decreased approximately $25 \%(0.06 \pm 0.01 \mathrm{nmol} \mathrm{EP} / \mathrm{mg}$ total protein $)$ compared to the antibody-treated CaATPase + phospholamban sample $(0.08 \pm 0.02 \mathrm{nmol}$ EP / mg total protein $)$. This phospholamban-dependent inhibition of Ca-ATPase EP level was similar to the effect of phospholamban on Ca-ATPase activity (Figure 5), and is consistent with previous studies of the effects of phospholamban on Ca-ATPase phosphorylation by ATP using insect cell microsome samples (Mahaney et al., 2000). Thus, the individual values of steady-state EP levels measured at the three temperatures were averaged to provide one EP level for each sample type, which were used in subsequent calculations of Ca-ATPase turnover. When expressed alone, the Ca-ATPase steady-state EP level was $0.09 \pm 0.02 \mathrm{nmol}$ EP / mg total protein, which was similar to the steady-state EP level of the antibody-treated Ca-ATPase + phospholamban sample.

\section{Effect of Phospholamban on Ca-ATPase Activation Energy.}

For each sample type studied, the ratio of Ca-ATPase activity (nmol ATP hydrolyzed per mg protein per second) to EP level (nmol ${ }^{32} \mathrm{P}$ bound per mg total protein) was calculated to determine the temperature dependence of the Ca-ATPase turnover 
number, $\mathrm{k}_{\mathrm{cat}}\left(\mathrm{s}^{-1}\right)$. The turnover number data was analyzed by an Arrhenius plot (Figure 7), and the slope $\left(E_{a} / R\right.$, where $R$ is the gas constant, $8.314 \mathrm{~J}$ per K per mole) of the plot provided the activation energy. The Arrhenius plot derived from the Ca-ATPase only and Ca-ATPase + phospholamban samples each consisted of two linear phases, with the break occurring at $15^{\circ} \mathrm{C}$, as has been documented previously (Bigelow et al., 1986). Use of two linear phases as opposed to one single line was justified by least squares analysis, which showed that the correlation coefficients of the two phases was significantly better than the correlation coefficient of a single line for each sample type (see legend of Figure 7). From the slopes of the individual plots, it was apparent that the Ca-ATPase in the absence of phospholamban (Figure 7, top) had a smaller activation energy above $15^{\circ} \mathrm{C}$ $(31 \pm 3 \mathrm{~J} / \mathrm{mol})$ relative to that of the Ca-ATPase in the presence of phospholamban (Figure 4, bottom), which was $51 \pm 5 \mathrm{~J} / \mathrm{mol}$. Treatment of the Ca-ATPase + phospholamban sample with 2D12 (Figure 4, bottom) had no significant effect on CaATPase activation energy $(52 \pm 5 \mathrm{~J} / \mathrm{mol})$. The finding that the activation energy of the antibody-treated Ca-ATPase + phospholamban sample was significantly different than the Ca-ATPase only sample was surprising in light of the activity and EP level experiments, which showed that the 2D12 antibody completely relieved Ca-ATPase inhibition by phospholamban. 

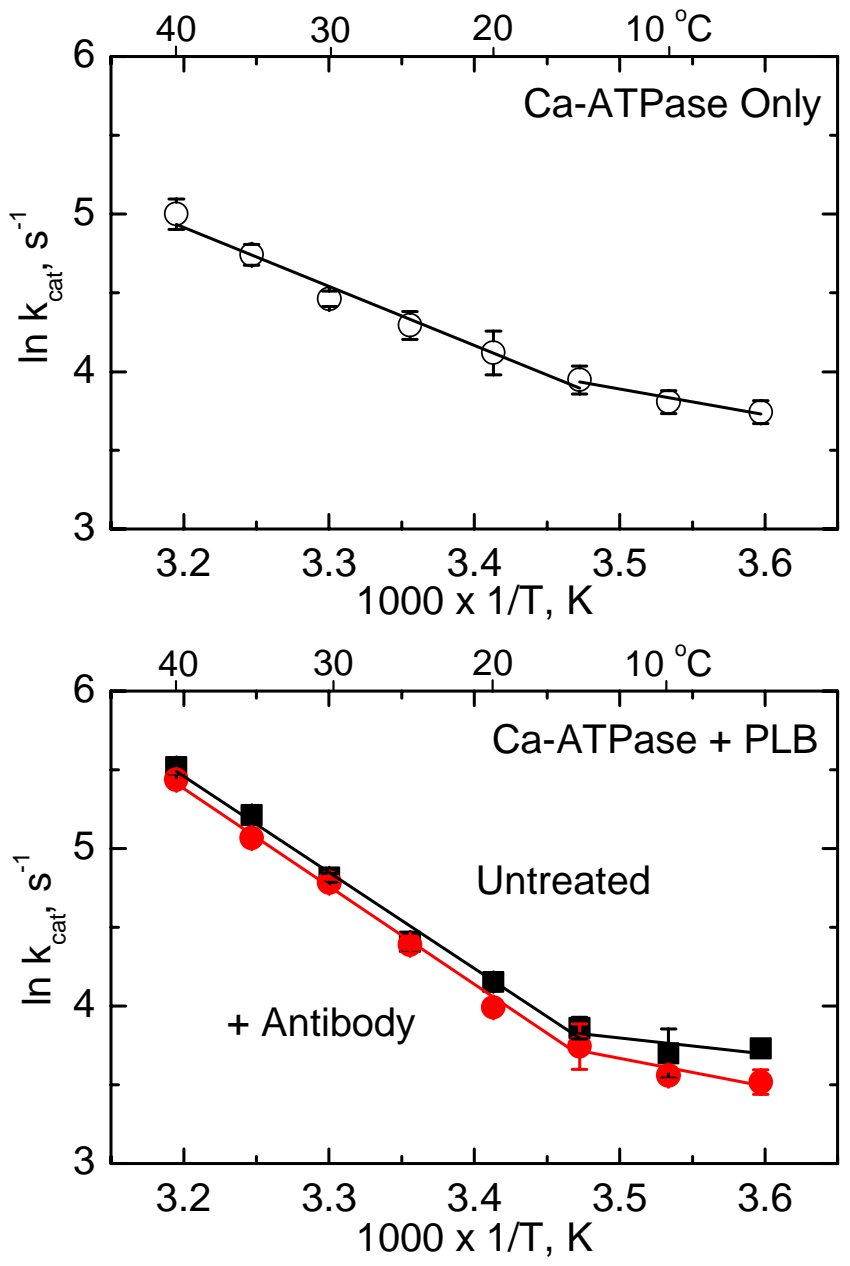
Figure 7: Effect of phospholamban on the temperature dependence of Ca-ATPase turnover number $\left(\mathbf{k}_{\mathbf{c a t}}\right)$. The temperature-dependent $\mathrm{Ca}$-ATPase turnover number at $\left[\mathrm{Ca}^{2+}\right]_{\text {free }}=270 \mathrm{nM}$ in the absence of phospholamban (Ca-ATPase Only, top panel) and in the presence of phospholamban (Ca-ATPase + PLB, bottom panel), was calculated from the activity data shown in Figure 6 and the catalytic site density of each sample type (described in the text). The symbols and sample conditions correspond to those defined in Figure 5. When plotted as shown in the figure (an Arrhenius plot), the slope coresponds to $-E_{a} / R$, where $E_{a}$ is the activation energy and $R$ is the gas constant. For each sample type, the plot consisted of two distinct and well-resolved phases with a break at $15{ }^{\circ} \mathrm{C}$. This was confirmed by least-squares analysis, which showed a significantly better correlation coefficient ( $\mathrm{r}$ ) for individual fits between $5-15{ }^{\circ} \mathrm{C}$ and $15-40{ }^{\circ} \mathrm{C}$ as opposed to one single fit from $5-40{ }^{\circ} \mathrm{C}$. The activation energies derived from the plots were: Ca-ATPase only, $13 \pm 2 \mathrm{~J} / \mathrm{mol}$ between $5-15{ }^{\circ} \mathrm{C}(\mathrm{r}=0.98)$ and $31 \pm 3 \mathrm{~J} / \mathrm{mol}$ between $15-40{ }^{\circ} \mathrm{C}(\mathrm{r}=0.991)$; untreated Ca-ATPase + phospholamban, $9 \pm 1 \mathrm{~J} / \mathrm{mol}$ between $5-15{ }^{\circ} \mathrm{C}(\mathrm{r}=0.75)$ and $51 \pm 5$ between $15-40^{\circ} \mathrm{C}(\mathrm{r}=0.99)$; and antibody-treated Ca-ATPase + phospholamban, $15 \pm 2 \mathrm{~J} / \mathrm{mol}$ between $5-15^{\circ} \mathrm{C}(\mathrm{r}=0.93)$ and $52 \pm 5 \mathrm{~J} / \mathrm{mol}$ between $15-40{ }^{\circ} \mathrm{C}(\mathrm{r}=0.99)$. 


\section{Chapter 4: Discussion}

\section{Overview.}

The purpose of this study was to test the hypothesis that phospholamban inhibits Ca-ATPase by increasing the activation energy required for enzyme turnover. To test this hypothesis, we conducted an Arrhenius analysis of the Ca-ATPase turnover number to determine Ca-ATPase activation energy in the absence and presence of phospholamban. The effect of phospholamban on the Ca-ATPase was further explored using a monoclonal antibody, 2D12, against phospholamban, which is known to relieve phospholamban inhibition of the Ca-ATPase similar to phospholamban phosphorylation. The results indicated that Ca-ATPase activation energy was significantly higher when phospholamban was present compared to that when phospholamban was absent. Surprisingly, there was no significant difference in Ca-ATPase activation energy for CaATPase + phospholamban samples treated with anti-phospholamban antibody versus those that were not treated, despite a significant increase in steady state Ca-ATPase activity following treatment with the antibody.

\section{The Baculovirus-insect Cell Ca-ATPase / Phospholamban Expression System.}

The samples used in this study were prepared using the baculovirus-High Five insect cell (fall army worm fibroblast) expression system for the Ca-ATPase and phospholamban. The advantage of using an expression system rather than native cardiac sarcoplasmic reticulum (SR) vesicles was the ability to study Ca-ATPase activation energy in the absence and presence of phospholamban. Because phospholamban is an 
endogenous integral membrane protein in cardiac SR, it is not possible to remove it from the membrane without the use of strong detergents or reagents that would change the fundamental physical properties of the membrane. The High Five cell expression system was based on a similar system using Sf21 insect cells (fall army worm ovarian cells), which was developed and characterized by Autry and Jones (1997) and in more detail by Mahaney et al. (2000). The High Five cells produced a greater amount of expressed CaATPase (and phospholamban) per mg of total protein, with better specific Ca-ATPase activity compared to protein expressed by the $\mathrm{Sf} 21$ cells. Thus, a single preparation of expressed protein provided sufficient material for a complete set of experiments, and the kinetics data obtained in each experimental set was of sufficient quality to allow for reproducibility even under the most stringent experimental conditions. The Mahaney laboratory and collaborators (manuscript in preparation) have characterized the physical and kinetic properties of the expressed Ca-ATPase, which were found to be nearly identical to the kinetic properties of the Ca-ATPase in native cardiac SR vesicles. Thus the High Five cell Ca-ATPase and phospholamban expression system was a valid model for studying the physical and kinetic mechanism by which phospholamban regulates the Ca-ATPase.

\section{Ca-ATPase Turnover Number.}

For this study, Ca-ATPase turnover was defined as the steady-state ATPase activity of the enzyme (nmoles ATP split per mg total protein per second) normalized to the catalytic site density of the enzyme in the samples (nmol EP per mg total protein). The resulting turnover number, $\mathrm{k}_{\text {cat }}$, had units of $\sec ^{-1}$. A simpler analysis using only the 
temperature-dependent enzyme velocity would have sufficed for this study. As such, one could normalize the Ca-ATPase activity of a given sample to the amount of expressed enzyme within that sample to facilitate the direct comparison of two different expressed samples. However, Mahaney et al. (2000) showed that despite nearly equal amounts of Ca-ATPase (per wt basis) in the insect cell microsome preps, Ca-ATPase in the presence of phospholamban has markedly lower steady-state activity than microsomes containing Ca-ATPase alone, even under experimental conditions that uncouple phospholamban from the Ca-ATPase (e.g., high $\left[\mathrm{Ca}^{2+}\right]$, anti-phospholamban antibody, phospholamban phosphorylation). Thus, the catalytic site density (steady-state phosphoenzyme formed) was an important factor to consider to understand the effect of phospholamban on the amount of kinetically competent Ca-ATPase in each sample type.

\section{Effect of Phospholamban on Ca-ATPase Activation Energy.}

The results of these experiments indicated that the presence of phospholamban increased Ca-ATPase activation energy by $167 \%$, from $31 \pm 3 \mathrm{~J} / \mathrm{mol}$ (Ca-ATPase only) to $52 \pm 5 \mathrm{~J} / \mathrm{mol}$ (Ca-ATPase + phospholamban). However the mechanistic basis of this effect is not yet clear. The Ca-ATPase enzyme cycle consists of a number of partial reactions, some of which are quite sensitive to the environmental conditions. Most notably, Froehlich and Taylor (1976) and Froehlich and Heller (1985) have shown that the three slowest steps in the enzyme cycle are calcium release from E2P, E2P.Ca 2 , and phosphoenzyme hydrolysis, E2P to $\mathrm{E} 2+\mathrm{P}_{\mathrm{i}}$, and the $\mathrm{E} 2$ to $\mathrm{E} 1$ transition. Because the rates of these transitions are all similar and highly interdependent, it is generally accepted that the rate of enzyme turnover is determined by the combination of the rates of these 
steps. Furthermore, the rate each of these steps is dependent on $\mathrm{pH},\left[\mathrm{Ca}^{2+}\right],[\mathrm{ATP}]$ and temperature. Because $\left[\mathrm{Ca}^{2+}\right]$ and $\mathrm{pH}$ were buffered, temperature was the only variable that changed significantly in these experiments. Nevertheless, temperature has significant effects on the relative rates of these three steps, and thereby changes which of the three steps is dominant for rate limitation for overall enzyme turnover. Thus, while we found that the presence of phospholamban changed the activation energy of the CaATPase, we cannot be certain whether one single step changed or a combination of steps within a series of reactions changed in response to phospholamban. The solution for this problem is to study the effect of phospholamban on the temperature dependence of each of the partial reactions in the Ca-ATPase cycle independently. This would show how phospholamban affects the activation energy of each individual step in the enzyme cycle, which in turn would reveal the mechanistic basis by which phospholamban inhibits CaATPase steady-state turnover.

Based on the effect of phospholamban on the $\left[\mathrm{Ca}^{2+}\right]$-dependence of Ca-ATPase activity (Figure 5), it is clear that phospholamban is a negative allosteric modulator of Ca-ATPase. Using this model, the Ca-ATPase would have two fundamental forms in equilibrium: a tense (or T) state, characterized as being less active with a decreased affinity for substrate (i.e., $\mathrm{Ca}^{2+}$ ) and a relaxed (or R) state, having greater activity and a higher substrate affinity (Figure 8). In the presence of phospholamban, the enzyme has decreased activity and a lower apparent $\mathrm{Ca}^{2+}$ affinity, indicating that phospholamban shifts the $\mathrm{T}$ to $\mathrm{R}$ equilibrium toward the $\mathrm{T}$ state, typical of a negative allosteric modulator. Because negative allosteric modulators are reversible inhibitors of enzymes, the presence of substrate at high enough levels can shift the $\mathrm{T}$ to $\mathrm{R}$ equilibrium back toward the $\mathrm{R}$ 


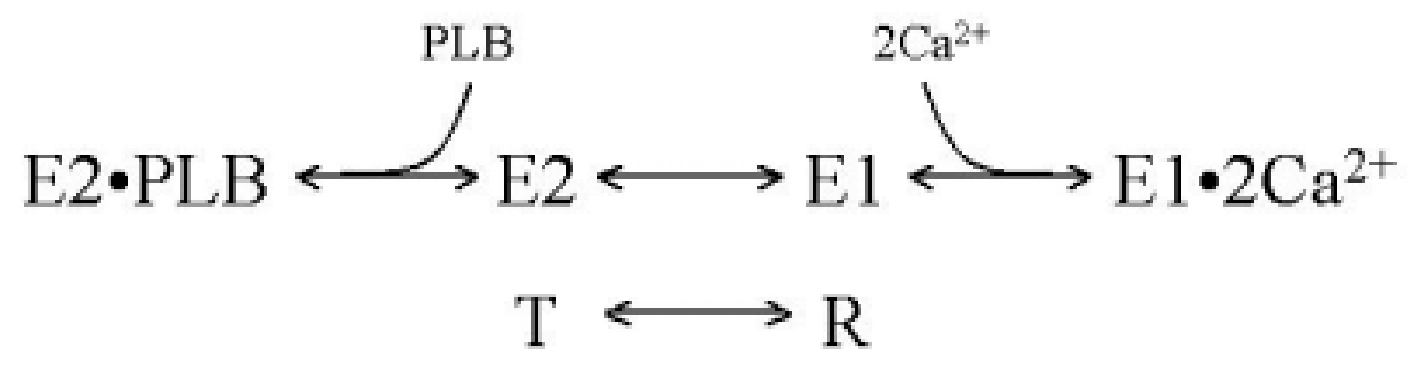

Figure 8: Phospholamban as a negative allosteric modulator of Ca-ATPase. The Ca-ATPase exists in two fundamental forms. The E1 state has high affinity for $\mathrm{Ca}^{2+}$ whereas the E2 state has low affinity for $\mathrm{Ca}^{2+}$. As such, the $\mathrm{E} 1$ form of the enzyme is considered the relaxed form ( $\mathrm{R}$ ), which readily binds $2 \mathrm{Ca}^{2+}$ ions cooperatively. Conversely, the E2 form is considered the tense form ( $\mathrm{T}$ ), which must first undergo a structural transition to $\mathrm{R}$ before $\mathrm{Ca}^{2+}$ can bind to the enzyme. Work in the Mahaney laboratory (unpublished results) has shown that phospholamban increases the E2 character of the enzyme, thus increasing the fraction of Ca-ATPase in the $\mathrm{T}$ form. However, increasing $\left[\mathrm{Ca}^{2+}\right]_{\text {free }}$ reverses this effect and saturating $\left[\mathrm{Ca}^{2+}\right]_{\text {free }}$ completely overcomes the effect of phospholamban on the Ca-ATPase. This behavior is consistent with phospholamban acting as a negative allosteric modulator of the Ca-ATPase. 
state, effectively reversing the effects of the modulator. This is true for the effect of phospholamban on Ca-ATPase activity. At high $\left[\mathrm{Ca}^{2+}\right]$, there is essentially no difference in the Ca-ATPase $\mathrm{V}_{\max }$ in the presence or absence of phospholamban.

Using a combination of rapid mixing kinetics techniques and time-resolved electron paramagnetic resonance spectroscopy, Mahaney et al. (1995) showed that CaATPase oligomeric interactions are important for high affinity $\mathrm{Ca}^{2+}$ binding and activation of ATP-dependent phosphoenzyme formation. Subsequently, Mahaney et al. (unpublished results) showed that during steady-state enzyme cycling, the Ca-ATPase operates as a tetrameric complex. At any given time, the four subunits within the tetramer correspond to the principal intermediates in the Ca-ATPase cycle: two E1 units $\left(\mathrm{Ca}_{2} \cdot \mathrm{E} 1 \cdot \mathrm{ATP}\right.$ and E1P) and two E2 units (E2P and E2). By modulating the reaction conditions, the authors showed that the distribution of E1 and E2 states could be shifted more towards E2, with a net decrease in apparent $\mathrm{Ca}^{2+}$ affinity, or toward E1, with a net increase in apparent $\mathrm{Ca}^{2+}$ affinity. Therefore, the Ca-ATPase $\mathrm{T}$ state is defined as an oligomeric complex with more E2 units, whereas the Ca-ATPase R state is an oligomeric complex with more E1 units. Both studies showed that the activation of $\mathrm{T}$ to $\mathrm{R}$ was rate limiting for enzymatic cycling.

Recent studies in the Mahaney laboratory have focused on the effect of phospholamban on Ca-ATPase oligomeric interactions using a variety of kinetic and spectroscopic approaches. Southall et al. (2001) used saturation transfer EPR to show that the presence of phospholamban results in a spatial reorientation of Ca-ATPase subunits within a Ca-ATPase oligomer relative to Ca-ATPase in the absence of phospholamban. Mahaney and coworkers (2002) using rapid mixing kinetics, and 
Waggoner et al. (2001) using fluorescence spectroscopy, showed that in the presence phospholamban, the Ca-ATPase had an increased E2 character relative to Ca-ATPase in the absence of phospholamban. The results of these studies suggest that phospholamban shifts the Ca-ATPase $\mathrm{T}$ to R equilibrium toward the $\mathrm{T}$ state.

Mahaney et al. (1995 and unpublished results) showed that the interconversion of Ca-ATPase oligomeric units from the less active ( $\mathrm{T}$ state) to more active ( $\mathrm{R}$ state) configuration was rate-limiting for the initiation of the enzyme cycle. Therefore, we propose that the activation energy measured in the present study corresponds to the energy required for the physical conversion of Ca-ATPase from the $\mathrm{T}$ to the $\mathrm{R}$ state preceding high affinity $\mathrm{Ca}^{2+}$ binding and ATP-dependent enzyme phosphorylation during the steady state. Because phospholamban shifts the $\mathrm{T}$ to $\mathrm{R}$ equilibrium more strongly toward the $\mathrm{T}$ state, greater energy is required for the activation of $\mathrm{T}$ to $\mathrm{R}$ in the presence of phospholamban than in the absence of phospholamban. A key test of this proposal would be to conduct the activation energy studies at a saturating $\left[\mathrm{Ca}^{2+}\right]$, where phospholamban is effectively uncoupled from the Ca-ATPase (e.g., $\left[\mathrm{Ca}^{2+}\right]>1 \mu \mathrm{M}$; Figure 2). Under these conditions, one would expect no phospholamban-dependent change in Ca-ATPase activation energy.

\section{Anti-phospholamban Antibody Had No Effect on Ca-ATPase Activation Energy.}

One aspect of the study that is difficult to account for is the lack of an effect on Ca-ATPase activation energy when the Ca-ATPase + phospholamban samples were treated with anti-phospholamban antibody (Figure 7). We found that treatment of the CaATPase + phospholamban samples with anti-phospholamban antibody did not result in a 
decrease in Ca-ATPase activation energy to a value similar to that observed for the CaATPase alone. This lack of change was not due to a failure of the antibody to uncouple phospholamban from the Ca-ATPase. A sufficient amount of antibody was used to maximize the stimulatory effects of uncoupling phospholamban, based on previous antibody titration experiments (Autry and Jones, 1997; Mahaney et al., 2000). As shown in Figure 3, treatment of the Ca-ATPase + phospholamban with the anti-phospholamban antibody resulted in a $20 \%$ stimulation of Ca-ATPase activity at $270 \mathrm{nM}\left[\mathrm{Ca}^{2+}\right]_{\text {free }}$, confirming the stimulatory effects of uncoupling phospholamban from the Ca-ATPase. Likewise, we found that antibody treatment stimulated Ca-ATPase EP formation by about $25 \%$, which was a similar increase as that observed for Ca-ATPase activity following antibody treatment. These trends were similar over most of the temperature range studied. Because turnover is defined as the ratio of Ca-ATPase velocity to EP level, and phospholamban decreased both kinetic parameters by a similar amount, the resultant Ca-ATPase activation energy did not change significantly following antibody treatment.

One possible interpretation of this result is that phospholamban may decrease CaATPase activity by completely inhibiting a fraction of enzyme, leaving the remaining enzyme fully active, rather than by inhibiting partially all the enzyme units. That is to say, because Ca-ATPase activity $=\mathrm{k}_{\mathrm{cat}} \mathrm{x}[\mathrm{E}]_{\mathrm{T}}$, a phospholamban-dependent decrease in the effective enzyme concentration would reduce enzyme activity without changing the turnover number (or presumably the temperature dependence of the turnover). It is well documented (see Chapter 1, Introduction) that phospholamban exists in equilibrium between active monomers and inactive pentameric forms. Thus, even at a molar 
stoichiometry of one to two phospholamban per one Ca-ATPase, one would expect only a fraction of Ca-ATPase to have bound phospholamban. This is consistent with phospholamban acting as a negative allosteric modulator of Ca-ATPase. While the $\mathrm{R}$ to $\mathrm{T}$ equilibrium is shifted toward the inactive $\mathrm{T}$ state, the remaining $\mathrm{R}$ state is completely active. As outlined above, a way to test this proposal would be to repeat the activation energy experiments at saturating $\left[\mathrm{Ca}^{2+}\right]_{\text {rree}}$, where phospholamban has essentially no effect on Ca-ATPase activity (Figure 2) or Ca-ATPase EP level (Mahaney et al., 2000).

An outstanding question which remains is why the activation energy measured for Ca-ATPase expressed alone was so different from that measured for the antibody-treated Ca-ATPase + phospholamban sample. It is possible that there was a fundamental difference in the physical environment of the Ca-ATPase in the absence and presence of phospholamban, that may have affected the thermodynamic or kinetic properties of the enzyme. However, this is unlikely because kinetics studies (Froehlich et al., 2002) and spectroscopic studies (Waggoner et al., 2001; Southall et al., 2001) using nearly identical samples have shown that the two sample types are highly similar in terms of physical and kinetics properties. Alternatively, it is possible that the thermodynamic and kinetics properties of the Ca-ATPase were fundamentally different in the absence of phospholamban than in the presence of phospholamban, even when phospholamban was physically uncoupled from the Ca-ATPase following antibody treatment. This seems unlikely, however, because the $\left[\mathrm{Ca}^{2+}\right]$-dependence of Ca-ATPase activity for the CaATPase in the presence of phospholamban treated with antibody was nearly identical to that of the Ca-ATPase alone (Figure 5). Clearly additional studies comparing the Ca- 
ATPase only and the antibody-treated Ca-ATPase + phospholamban sample are needed to understand this lack of effect.

Future directions: The studies of this project have provided good evidence that phospholamban increases the activation energy of the Ca-ATPase. More detailed studies directed at understanding the effect of phospholamban on individual reactions in the CaATPase cycle will help elucidate the mechanistic and thermodynamic bases by which phospholamban inhibits Ca-ATPase activity. 


\section{Chapter 5: References}

Alpert N. and Gordon M. (1962). Myofibrillar adenosine triphosphate activity in congestive heart failure. Am J Physiol 202, H940-6

Arkin, I. T., Rothman, M., Ludlam, C. F. C., Aimoto, S., Engelman, D. M., Rothschild,

Autry, JM., and Jones, LR. 1997. Functional coexpression of the canine cardiac Capump and phospholamban in Spodoptera frugiperda (SF21) cells reveals new insights on ATPase regulation. J. Biol. Chem. 272: 15872-15880.

Balke, CW., Shorofsky, SR. 1998. Alterations in calcium handling in cardiac hypertrophy and heart failure. Cardiovascc. Res; 37: 290-299.

Berne, A.M., Levy, M.N. 1997. Cardiovascular Physiology. Mosby-YearBook. St. Louis.

Berridge, M.J. 1997. Elementary and global aspects of calcium signaling. J. Physiol (London). 499: 291-306.

Bers, D.M.1991. Excitation-Contraction coupling and cardiac contractile force Norwel: Kluwer academic publishers.

Davis, B. A., I. Edes, R. C. Gupta, E. F. Young, H. W. Kim, N. A. E. Steenaart, G. Szymanska, and Kranias E. G. (1990). The role of phospholamban in the regulation of calcium transport by cardiac sarcoplasmic reticulum. Mol. Cell. Biochem. 99: 83-88,

Dupont, Y., Pougeois, R., Ronjat, M. and Verjovsky-Almeida, S. (1985) ATP. J. Biol. Chem. 260, 7241-7249

Fabiato, A. (1985). Time and calcium dependence of activation and inactivation of calcium-induced release of calcium from the sarcoplasmic reticulum of a skinned canine cardiac Purkinje cell. J. Gen. Physiol. 85, 247-289. 
Feher, JJ., Fabiato, A. 1990. Cardiac sarcoplasmic reticulum: calcium uptake and release. In: Langer, GA., editor. Calcium and the heart. New York: Raven Press; $199-268$

Froehlich, J. P., and E. W. Taylor. 1976. Transient state kinetic effects of calcium ion on sarcoplasmic reticulum adenosine triphosphatase. J. Biol. Chem. 251: 2307-2315.

Froehlich, J., Mahaney, J., Kutchai, H., Jones, L., Southall, J., and Albers, J. 2002. Cardiac Ca-ATPase (SERCA2a) Expressed without Phosphoplamban (PLB) Behaves Like SERCA1 with Respect to Interactions with ATP and ADP in Transient Kinetic Experiments. Biophys. J., 80(2): 264a.

Froehlich, J.P., and Heller, P.F. 1985. Transient State Kinetics of the ADP-Insensitive Phosphoenzyme in Sarcoplasmic Reticulum: Implications for Transient-State Calcium Location. Biochemistry. 24: 126-136.

Fujii, J., Kadoma, M. Tada, M., Toda, H and Sakiyama, F (1986) Biochem. Biophys. Res. Commun. 138, 1044-1050

Huggins, J. P., Cook, E. A. Piggott, J. R Mattnsley, T. J. and. Engalnd, P. J. Phospholamban is a good substrate for cyclic GMP-dependent protein kinase in vitro, but not in intact cardiac or smooth muscle. Biochem. J. 260: 829-835, 1989. J. Biol. Chem. 263, 18364-18368

Jorgensen, A.O and Jones, L. R.( 1987). Immunoelectron microscopical localization of phospholamban in adult canine ventricular muscle. J. Cell Biol. 104: 1343-1352. K. J., and Smith, S. O. (1995) J. Mol. Biol. 248, 824-834

Katz A.M. Physiology of the Heart. New York: Raven Press; 1992. 
Katz, AM., Takenaka, H., Watras, J. 1986. The sarcoplasmic reticulum. In: Fozzard, HA., Haber, E., Jennings, RB., Katz, AM, editors. The heart and cardiovascular system: Scientific Foundations. New York: Raven Press; 61-100.

Kimura, Y.,. Kurzydlowski, K Tada, M. and Maclenan, D. H. (1996) Phospholamban regulates the $\mathrm{Ca}^{2+}$-ATPase through intra-membrane interactions. J. Biol. Chem. 271: $21726-21731$,

Kirchberger, M. A., Tada, M. and Katz, A. M. Adenosine 3': 5'-monophosphatedependent protein kinase catalyzed phosphorylation reaction and its relationship to calcium transport in cardiac sarcoplasmic reticulum. J. Biol. Chem. 249: 6166$6173,1974$.

Knowlton A, Connelly C, Romo G, (1992). Rapid expression of fibronectin in rabbit heart following myocardial infarction with and without reperfusion. J Clinical invest. 89, 1060-1068.

Kovacs, R. J., Nelson, M. T., Simmerman, H. K. B., and Jones, L. R. (1988)

Kranias, E. G. Regulation of $\mathrm{Ca}^{2+}$ transport by cyclic $3 *, 5^{*}$-AMP-dependent and calcium-calmodulin-dependent phosphorylation of cardiac sarcoplasmic reticulum. Biochim. Biophys. Acta 844: 193-199, 1985.

Lacapere, J.J., Gingold, M.P., Champeil, P. and Guillain, F. (1981) J. Biol. Chem. 256, $2302-2306$

Limas C, Olivari M-T, Goldenberg, T. Benditt, D. Simon, A. 1987. Calcium uptake by cardiac sarcoplasmic reticulum in human dilated cardiomyopathy. Cardiovasc Res 21, 601-605. 
Lompre, A.-M., Anger, M. and Levitsy, D. 1994. Sarco(endo)plasmic reticulum calcium pumps in the cardiovascular system: function and gene expression. J. Mol. Cell. Cardiol. 26: 1109-1121.

MacLennan, D. H., Brandl, C. J., Korczak, B. and Green, N. M. (1985) Nature 405, 647655.

Mahaney, J.E., Froehlich, J.P., and Thomas, D.D. 1995. Conformational Transitions of the Sarcoplasmic Reticulum Ca-ATPase Studied by Time-resolved EPR and Quench Flow Kinetics. Biochemistry. 34: 4864-4879.

Mitchell, M. B., Meng, X., Ao, L., Brown, M. J., Harken, A. H. 1995. Preconditioning of isolated rat heart is mediated by protein kinase C. Circ Res. 76, 73-81.

Morad, M. and Cleeman, L. (1987) J. Mol. Cell Cardiol. 19, 527-553.

Mukherjee R., Spinale, FG. 1998. L-type calcium channel abundance and function with cardiac hypertrophy and failure. J. Mol. Cell. Cardiol. 30: 1899-1916.

Philipson, K.D. The cardiac $\mathrm{Na}^{+} / \mathrm{Ca}^{2+}$ exchanger. In: Langer, GA, editor; Calcium and the heart. New York: Raven Press; 1990. p. 85-108.

Reinstein, J. and Jencks, W. P. (1993) The binding of ATP and $\mathrm{Mg}^{2+}$ to the calcium adenosine triphosphatase of sarcoplasmic reticulum follows a random mechanism. Biochemistry 32, 6632 \pm 6642

Schaper J, Froede R, Hein S. 1991. Impairment of myocardial ultrastructural changes of the cytoskeleton in dilated cardiomypathy. Circulation. 83, 504-514

Sham, J. S. K., Jones, L. R., and Morad, M. (1991) Am. J. Physiol. 261, H1344-H1349

Sheu, S., Blaustein, MP. 1986. Sodium/calcium exchange and regulation of cell calcium and contractility in cardiac muscle with a note about vascular smooth muscle. In: 
Fozzard, HA., Haber, E., Jennings, RB., Katz, AM., editors. The heart and cardiovascular system: Scientific Foundations. New York: Raven Press; 509-536.

Southall, J., Huffman, J., Jones, L., and Mahaney, J. 2001. EPR Studies of the Cardiac Ca-ATPase Expressed in Insect Cells: Effect of Phospholamban on Ca-ATPase Oligomeric Interactions. Biophys. J,. 80(1): 432a.

Stokes, D.L and Green, N.M. (2000). Modeling a dehalogenase fold into the $8 \AA$ density map of CaATPase defines a new domain structure. Biophys J. 78, 1765-1776

Tada, M., and A. Katz, A. M. Phosphorylation of the sarcoplasmic reticulum and sarcolemma. Annu. Rev. Physiol. 44: 401-423, 1982.

Tada, M., Kirchberger, M. A, and. 1975. Phosphorylation of a 22,000-dalton component of the cardiac sarcoplasmic reticulum by adenosine 3', 5'-monophosphatedependent protein kinase. J. Biol. Chem. 250: 2640-2647.

Toyoshima, C., Nakasako, M. and Ogawa, H. (2000) Crystal structure of the calcium pump of sarcoplasmic reticulum at $2.6 \AA$ resolution. Nature $405,647-655$.

Toyoshima, C., Nakasako, M. and Ogawa, H. (2000). Nature (London) 405, 647-655

Unverferth, D., Lee, S., and Et, W. (1988) Human myocardial adenosine triphosphate activities in health and heart failure. Am. Heart J. 115, 139-146.

Waggoner, J. Huffman, J., Kupec, J., Jones, L. and Mahaney, J. 2001. Fluorescence Studies of the Cardiac Ca-ATPase Expressed in Insect Cells: Effect of Phospholamban on Ca-ATPase Conformational States. Biophys. J,. 80(1): 432a.

Walker, CA., Spinale, FG. 1999. The structure and function of the cardiac myocyte: A review of fundamental concepts. J. thorac. Cardiovasc Surg. 118: 375-382.

Wegener, A. D., and Jones, L. R. (1984) J.Biol. Chem. 259, 1834-1841. 


\section{Appendix}

28th October 2002

Dear Patrick Apopa,

Nature, hereby grants permission for the reproduction of figure 2 from, Nature 405:647-655(2000), providing that the authors agree, (please see original article for contact details) and the following credit line is used:

Reprinted by permission from Nature (reference citation) copyright (year)

Macmillan Publishers Ltd.

For electronic purposes, the word Nature must be hyperlinked to the Nature

homepage at www.nature.com/nature

Yours sincerely,

Puja Bharadwa

Nature Permissions

Puja Bharadwa

Nature Permissions

The Macmillan Building

4-6 Crinan Street

London

N1 9XW

Tel: $44(0) 2078334561$

Fax: 44 (0)207 8434596

permissions@nature.com

http://www.nature.com 
Dear Patrick

$>$ Dear Authors,

$>$

$>$ My name is Patrick Apopa and I am a graduate student at West Virginia $>$ University. Currently $\mathrm{i}$ am working on the writing of my Thesis

> entitled, Thermodynamic effects of Phospholamban on CaATPase kinetics.

$>$ I have been granted permission by Nature to reproduce part

$>$ of Figure 2 from your paper published in 8 JUNE 2000 (Vol. 405, pp

$>647-655$ ). I therefore kindly ask you to grant me permission on the same.

$>$ Appropriate attribution to Nature and the said authers will be provided.

$>$ Thankyou in advance.

$>$ Patrick Apopa

Of course you may use Fig 2 of my Nature paper $(405: 647-655,2000)$ in your thesis.

Yours sincerely

Chikashi Toyoshima

Professor of Supramolecular structure

Institute of Molecular and Cellular Biosciences

The University of Tokyo 


\section{Curriculum Vitae \\ Patrick L. Apopa \\ 4 November 2002}

\section{Department of Biochemistry and Molecular Pharmacology \\ PO Box 9142 \\ West Virginia University, Morgantown, WV 26506 \\ Phone: 304-293-0225 (w) 304-293-5847 (h)}

Fax: 304-293-6846

e-mail:papopa@mix.wvu.edu

\section{Personal Data:}

Birthdate and Place: February 23, 1968; Siaya, Kenya

Address: $\quad 367$ Newton Avenue,

Morgantown,WV, 26505

Family: $\quad$ Married, one child.

\section{Education:}

1992 BSc.

Zoology and Biochemistry, University of Nairobi, Kenya

1998 MSc.

Biochemistry, University of Nairobi, Kenya

2002 MS.

Biochemistry, West Virginia University, Morgantown,WV

Advisor: James E. Mahaney, Ph.D

Thesis: Thermodynamic effects of phospholamban on

Ca-ATPase Kinetics (focus is on cardiac Ca-ATPase isoform)

Areas of specialization: Enzyme Kinetics, Protein

Mobility,

Lipid Bilayer Dynamics,

\section{Teaching Experience, WVU:}

Department of Biochemistry

2001 - Biochemistry 339 undergraduate Lab, Lab assistant

\section{Service Activities, WVU:}

Department of Biochemistry

2001-2002 Biochemistry Graduate Student Representative 


\title{
Seminars Presented:
}

\author{
2001 - present: Biochemistry Research Forums (one per year) \\ 2002 - present: Biochemistry Research Forums (one per year) \\ 2001 - Biochemistry 496 Graduate Student Seminar: 30 Sept. 1999 \\ "Malaria:The export of a trafficking pathway in Plasmodium \\ infected erythrocytes"
}

\section{Manuscripts in Preparation:}

\section{Work History:}

1993-1996: Medical sales Representative, Philips Pharmaceuticals

1997-2000: Medical Representative, Hoechst Marion Roussel Pharmaceuticals

2000-Present: Graduate student, WVU, Department of Biochemistry and Molecular Pharmacolocgy

\section{Personal References:}

\author{
Jim Mahaney (Ph.D) \\ 1414 Brockton Dr. \\ Morgantown, WV 26508 \\ (304)-292-5767 (Home) \\ (304)-293-7756 (Work/Daytime \#)
}

\section{Work Related References:}

Jim Mahaney (Ph.D) 1414 Brockton Dr. Morgantown, WV 26508 (304)-292-5767 (Home) (304)-293-7756 (Work/Daytime \#) 
John Durham (Ph.D)

20 Chasewood Lane

Morgantown, WV 26508

(304)-291-8350 (Home)

(304)-293-7757 (Work/Daytime \#)

Jason R. Waggoner

Apt. F 1293 VanVoorhis Rd.

Morgantown, WV 26505

(304)-598-2760 (Home)

(304)-293-0225 (Work/Daytime \#) 